Portland State University

PDXScholar

\title{
How Will Autonomous Vehicles Change Local Government Budgeting and Finance? Case Studies of On-Street Parking, Curb Management, and Solid Waste Collection
}

Benjamin Y. Clark

University of Oregon, bclark2@uoregon.edu

Follow this and additional works at: https://pdxscholar.library.pdx.edu/trec_reports

Part of the Transportation Commons, Urban Studies Commons, and the Urban Studies and Planning Commons

Let us know how access to this document benefits you.

\section{Recommended Citation}

Clark, Benjamin Y. How Will Autonomous Vehicles Change Local Government Budgeting and Finance? Case Studies of On-Street Parking, Curb Management, and Solid Waste Collection. NITC-SS-1174. Portland, OR: Transportation Research and Education Center (TREC), 2019. https://doi.org/10.15760/ trec. 217

This Report is brought to you for free and open access. It has been accepted for inclusion in TREC Final Reports by an authorized administrator of PDXScholar. Please contact us if we can make this document more accessible: pdxscholar@pdx.edu. 

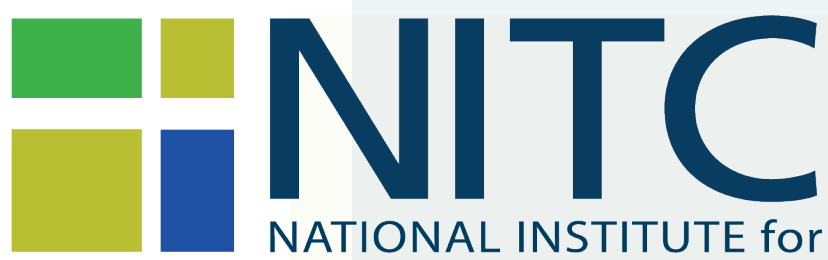

NATIONAL INSTITUTE for

TRANSPORTATION and COMMUNITIES

FINAL REPORT

How Will Autonomous Vehicles Change Local Government Budgeting and Finance? Case Studies of On-Street Parking, Curb Management, and Solid Waste Collection

NITC-SS-1174 May 2019

NITC is a U.S. Department of Transportation national university transportation center.

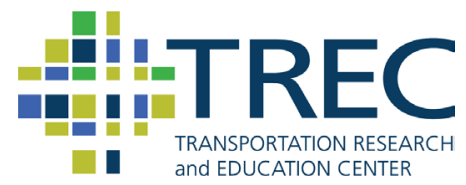




\title{
How Will Autonomous Vehicles Change Local Government Budgeting and Finance? Case Studies of On-Street Parking, Curb Management, and Solid Waste Collection
}

\author{
Final Report \\ NITC-SS-1174 \\ by \\ Benjamin Y. Clark \\ Associate Professor \\ School of Planning, Public Policy and Management \\ University of Oregon \\ bclark2@uoregon.edu \\ http://bit.ly/BenClark \\ orcid.org/0000-0002-8627-7857
}

for

National Institute for Transportation and Communities (NITC)

P.O. Box 751

Portland, OR 97207
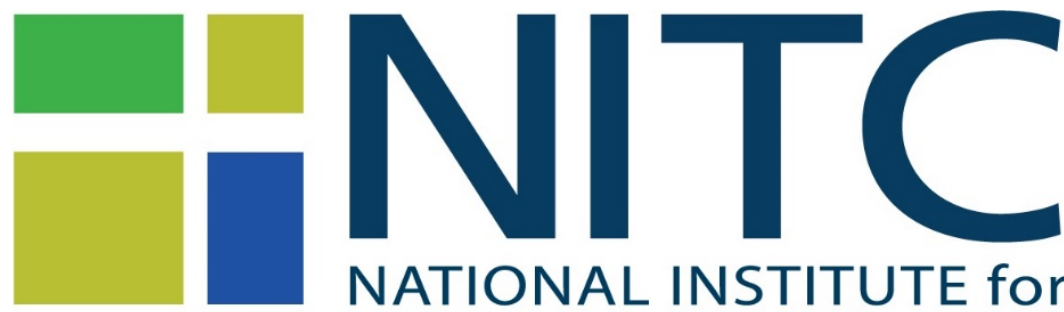

NATIONAL INSTITUTE for

TRANSPORTATION and COMMUNITIES

May 2019 


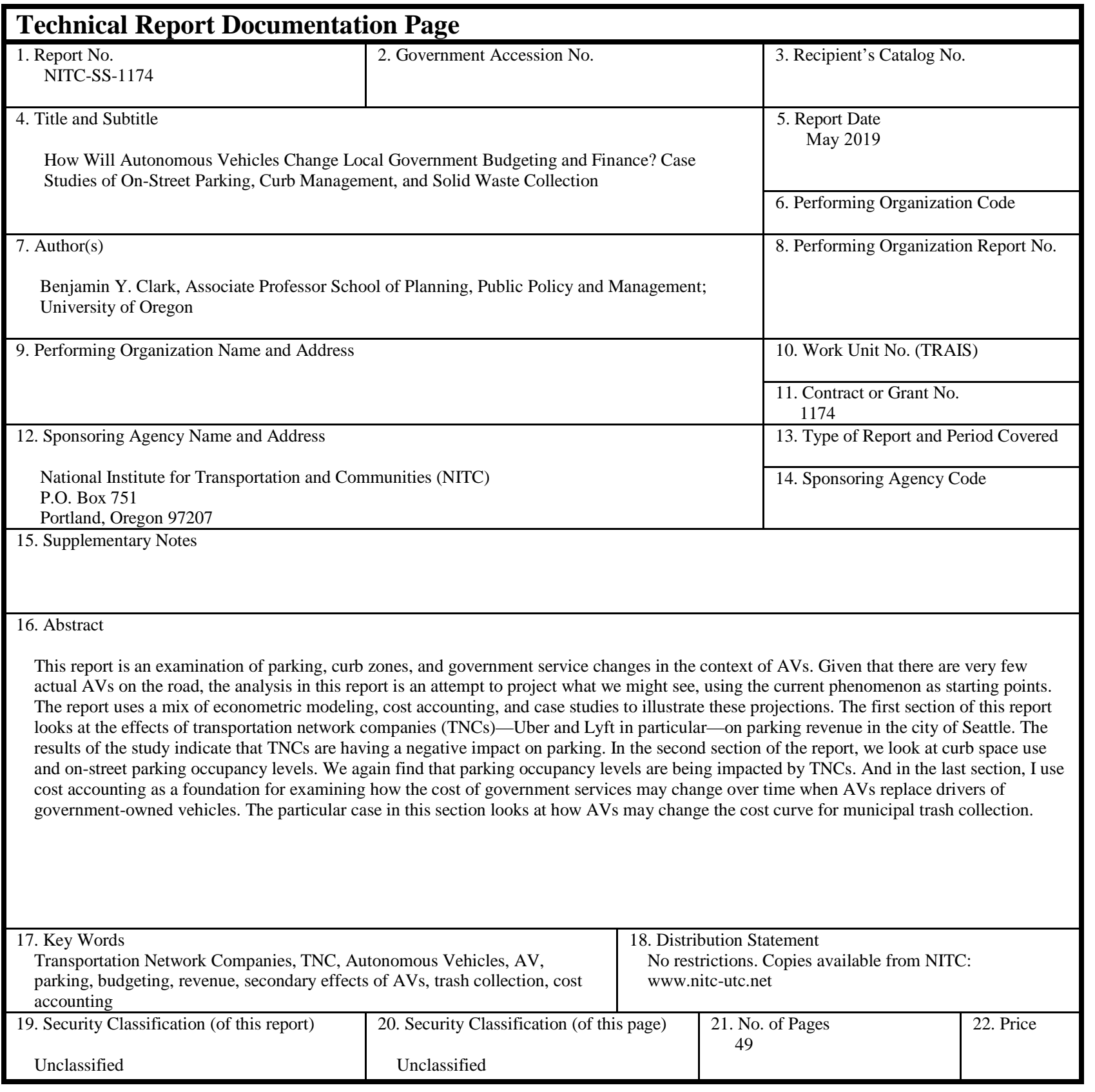




\section{ACKNOWLEDGEMENTS}

This project was funded by the National Institute for Transportation and Communities (NITC; grant number 1174 - 2452A0), a U.S. DOT University Transportation Center. Funding support was also provided by the University of Oregon's Urbanism Next Research Initiative and the Oregon Policy Lab.

I would like to acknowledge the assistance of all shapes and sizes that came from Anne Brown, Rebecca Lewis, Marsha Gravesen, Nico Larco, Marc Schlossberg, and Becky Steckler.

\section{DISCLAIMER}

The contents of this report reflect the views of the authors, who are solely responsible for the facts and the accuracy of the material and information presented herein. This document is disseminated under the sponsorship of the U.S. Department of Transportation University Transportation Centers Program in the interest of information exchange. The U.S. Government assumes no liability for the contents or use thereof. The contents do not necessarily reflect the official views of the U.S. Government. This report does not constitute a standard, specification, or regulation.

\section{RECOMMENDED CITATION}

Clark, Benjamin Y. How Will Autonomous Vehicles Change Local Government Budgeting and Finance? Case Studies of On-Street Parking, Curb Management, and Solid Waste Collection. NITC-SS-1174. Portland, OR: Transportation Research and Education Center (TREC), 2019. 


\section{TABLE OF CONTENTS}

EXCUTIVE SUMMARY .................................................................................................................... 6

1.0 HOW WILL AUTONOMOUS VEHICLES CHANGE LOCAL GOVERNMENT BUDGETING AND FINANCE? TNCS AS LEADING CASE FOR AVS............................. 7

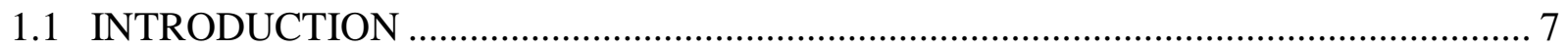

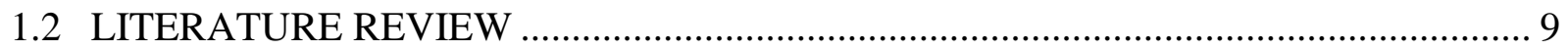

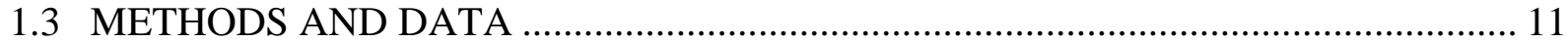

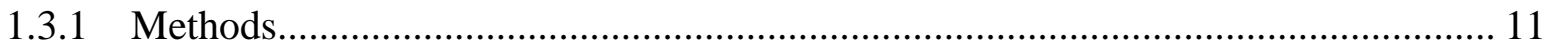

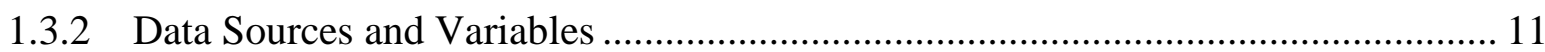

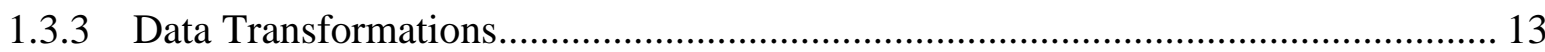

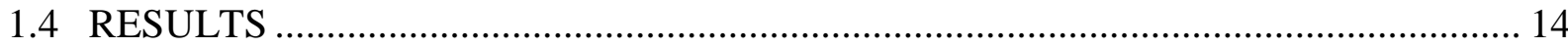

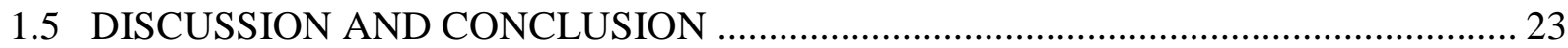

\subsection{RECLAIMING THE CURB AND DITCHING THE LOT IN AN ERA OF TNCS}

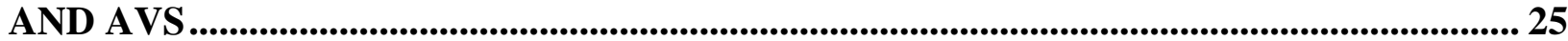

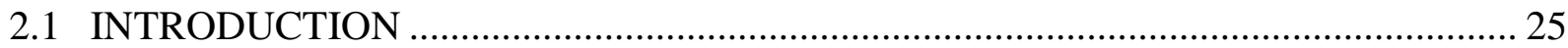

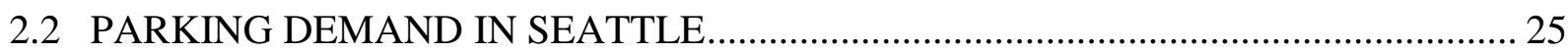

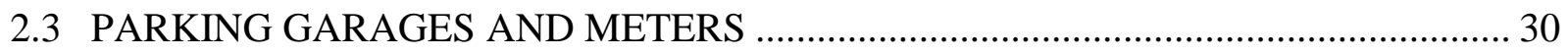

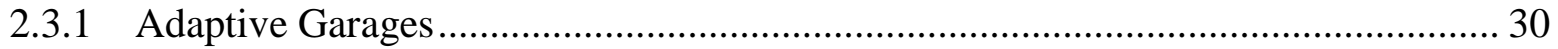

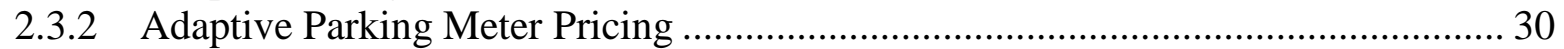

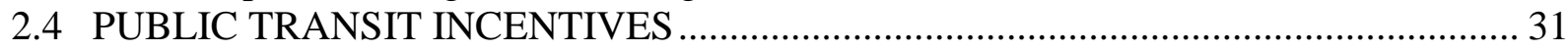

2.4.1 Cashing Out a "Free” Parking Space to Buy Transit........................................... 31

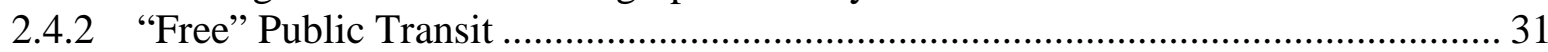

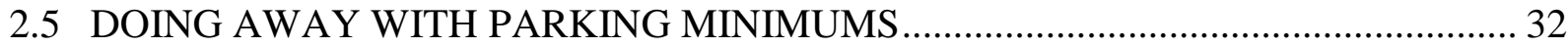

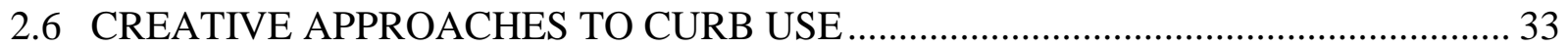

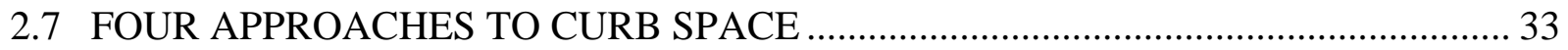

2.7.1 Curb Strategy 1: Flex Zones ............................................................................ 33

2.7.2 Curb Strategy 2: Transit-Conscious Planning................................................. 34

2.7.3 Curb Strategy 3: Reconfiguring Access and Loading Zones .................................. 34

2.7.4 Curb Strategy 4: Considering Tradeoffs .......................................................... 34

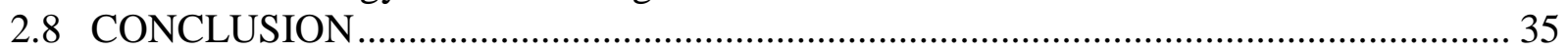

3.0 THE IMPACTS OF AVS ON LOCAL GOVERNMENT BUDGETING AND FINANCE: CASE OF SOLID WASTE COLLECTION PARAGRAPH FORMAT .......... 37

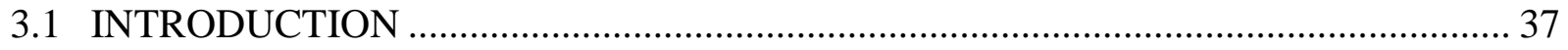

3.2 CURRENT TRENDS TOWARD AUTOMATION ................................................... 38

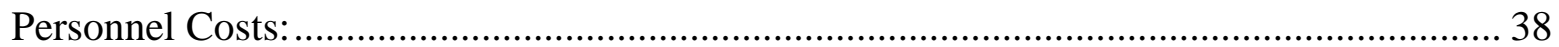

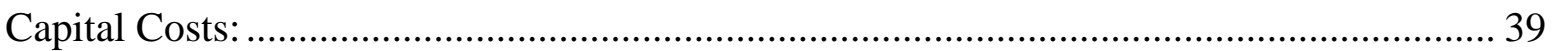

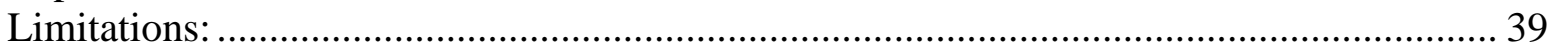

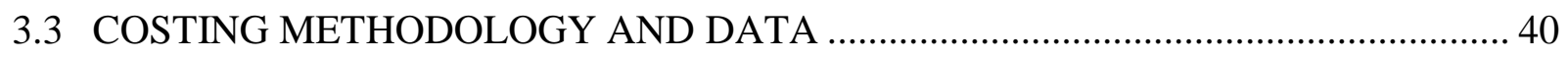

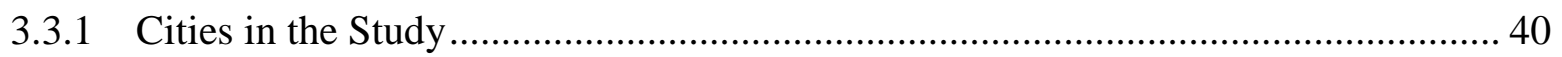

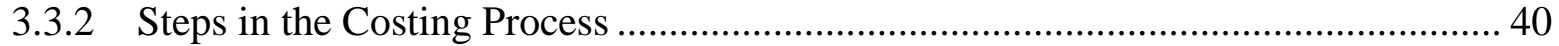

3.3.3 Assumptions Made for Each City ................................................................. 41

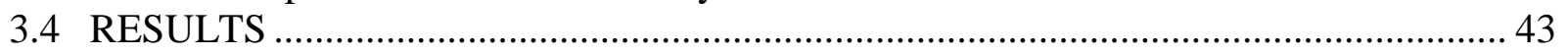

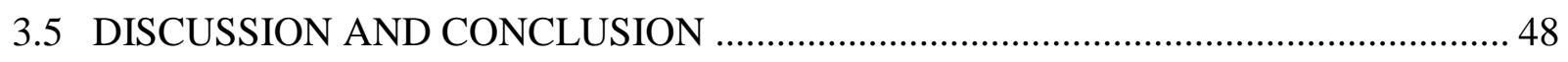

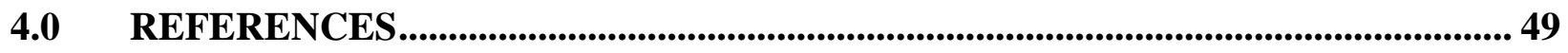




\section{LIST OF TABLES}

Table 1.1: Ordinary Least Squared Models 1 and 2 .............................................. 17

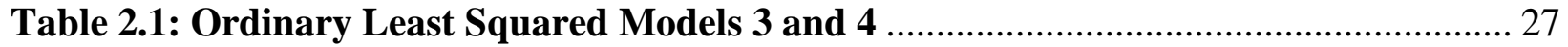

\section{LIST OF FIGURES}

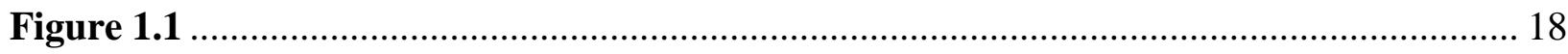

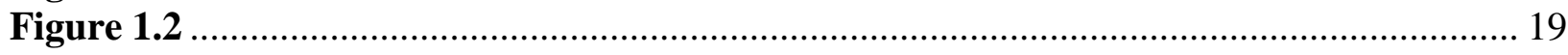

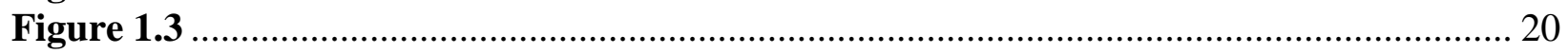

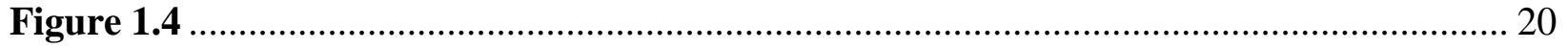

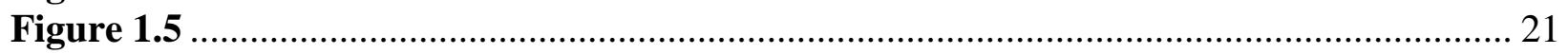

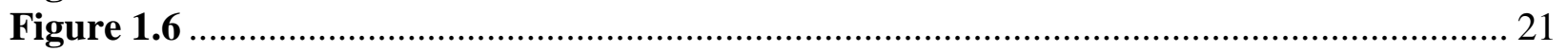

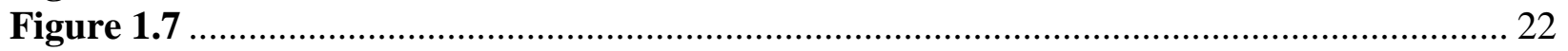

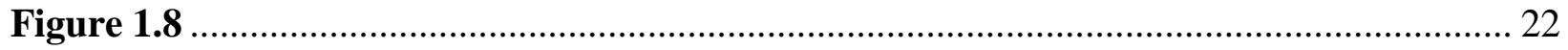

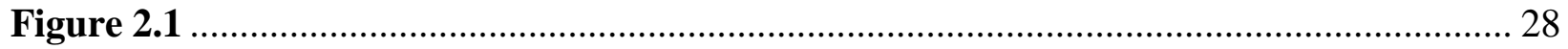

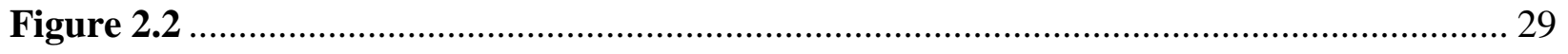

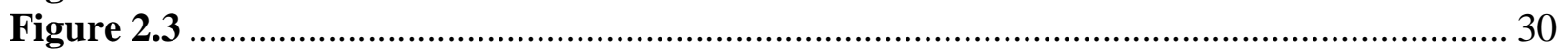

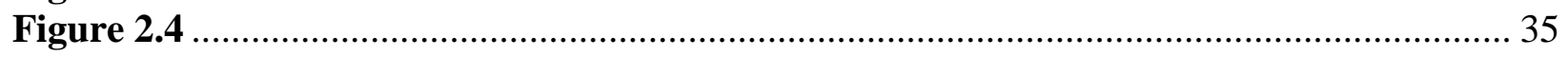

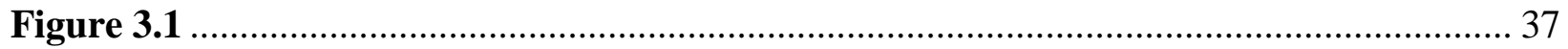

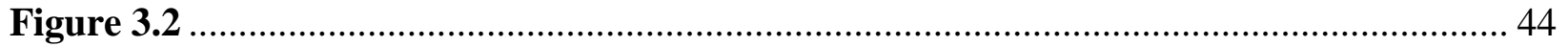

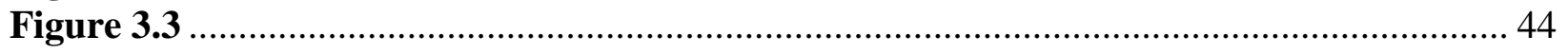

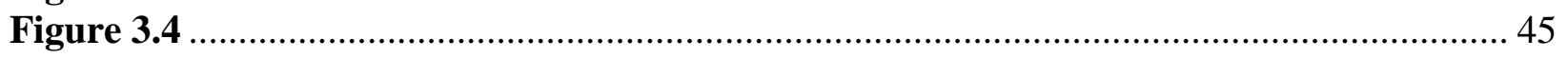

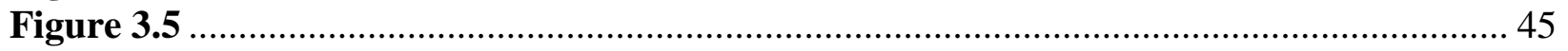

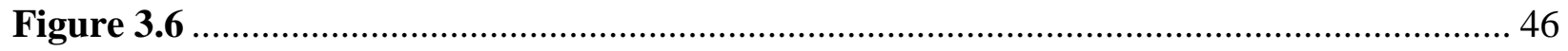

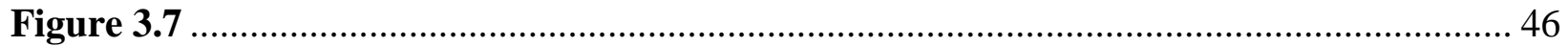

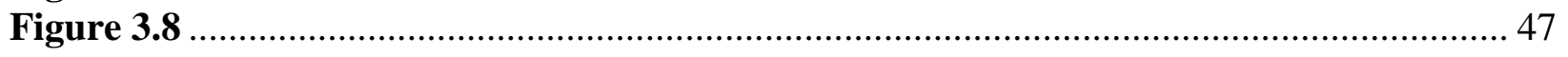

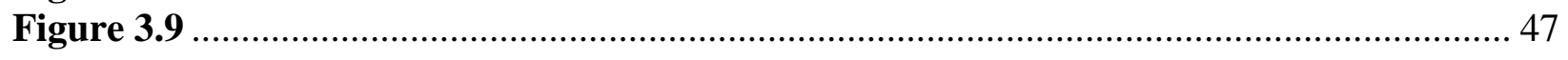




\section{EXCUTIVE SUMMARY}

The challenges that Autonomous Vehicles (AVs) will impose upon cities are both currently difficult to fully envision and critical to begin to address. This report makes an incremental step toward quantifying the impacts that AVs will have and provides insight on how cities may be able to adjust policies to avoid mistakes made in with changes to the transportation modalities in earlier eras.

This report is an examination of parking, curb zones, and government service changes in the context of AVs. Given that there are very few actual AVs on the road, the analysis in this report is an attempt to project what we might see, using the current phenomenon as starting points. The report uses a mix of econometric modeling, cost accounting, and case studies to illustrate these projections.

The first section of this study looks at the effects of transportation network companies (TNCs) Uber and Lyft in particular-on parking revenue in the city of Seattle. TNCs are viewed by many as a clear precursor to AVs because in many ways they operate as AVs will—it is just that right now TNCs have drivers, but will not in the future. Thus we can make some assumptions that how people use TNCs will mimic AVs in many ways. In this section of the report, I find that revenue is likely to decrease by about one percent for each one thousand additional TNC trips taken if no policy changes are taken. The effects on revenue will vary quite widely by neighborhood - thus a one-size-fits-all policy may not be the best path forward for cities. Flexible and adaptable policies that can more quickly respond (or better yet be proactive) will be better suited at managing the changes that will affect parking revenue.

In the second section of the report, we look at curb space use and on-street parking occupancy levels. This section, again, draws some empirical evidence from Seattle but also looks to what is happening around the country in how curbs are being managed or could be when more trips rely on TNC or AVs. We find that on-street parking occupancy, like parking revenue, is going to be negatively impacted by increased use of TNCs. It is expected that with no policy changes that occupancy will decline by about 12 percent for each additional one thousand trips. As was the case for revenue, the declines in occupancy are varied by neighborhood-with each having its own unique downward slope. Not surprisingly, neighborhoods that currently have the most congested or occupied on-street parking situation are likely to see the greatest change as TNC use expands.

In the last section, I use cost accounting as a foundation for examining how the cost of government services may change over time when AVs replace drivers of government-owned vehicles. The specific case this section looks at is trash collection, using data from a number of North Carolina cities as the starting point of the analysis. The results from this section suggest that the cities that currently employ very little automation for trash collection because of street design (lots of on-street parking, for example) will likely see the greatest benefits to AV 
advances. Automation is not new to refuse collection, but AVs have the potential to create flexibility in operations in ways that current technology does not afford.

\subsection{HOW WILL AUTONOMOUS VEHICLES CHANGE LOCAL GOVERNMENT BUDGETING AND FINANCE? TNCS AS LEADING CASE FOR AVS}

\subsection{INTRODUCTION}

Fifteen years ago, autonomous vehicles (AVs) were more fiction than science. Today, AVs have driven millions of miles, but a number of design, planning, and financial challenges remain (Brodsky 2016; Glancy 2015). It is quite clear that AVs will drastically change transportation and will have a wider impact on equity and the equitable distribution of the new infrastructure required to accommodate them, reshuffle city development patterns, and alter land valuationleading to strains on government finances. October 2016 marked the first exclusively AV delivery of freight (Davies, 2016), while September 2016 marked the introduction of a fully AV fleet of Uber vehicles in two cities - though Uber did later see a setback with this deployment and halt the program. However, the current level of AV deployment is not yet sufficient to evaluate how they might actually impact city environments and budgets. What we do have that approximates this technology are transportation network companies (TNCs) such as Uber and Lyft.

Review of the TRD TRID database makes it clear that there is a proliferation of research around the technological aspects of AVs, but research on their secondary effects is only starting to be understood (Glancy 2015; Mitteregger et al. 2019; Terry and Bachmann 2019). This report specifically seeks to study those secondary effects, not the innovations themselves but how innovations impact the municipal budget—parking revenue in particular. There has been little work to date that has investigated the budgetary impacts of AVs or TNCs on municipal budgeting and finance. Clark, Larco, and Mann (2017) provide some of the first explorations of the topic by providing an overview of AV impacts across a city budget. However, this study proposed directional impact and did not quantify the magnitude of these impacts. Clark and Lewis (2018) provide some limited budgetary impacts in three case study cities across a number of revenue categories, but this study is not based on an empirical evaluation of what is currently happening on the ground. Mitteregger et al. (2019) examine the case of Vienna, Austria and the projected fiscal impacts on that city. Mike Maciag's (2017) article in Governing Magazine has been one of the few articles in the popular press to question empirically how autonomous vehicles might impact local government budgets. He notes that in his study of 25 large U.S. cities that parking revenues (meters, garages, fines/fees) account for an average of \$129/capita in revenue. He notes that city " $[\mathrm{t}]$ otals were much larger in cities assessing special taxes on parking operators, deploying traffic cameras or those receiving substantial shared revenues from states in the form of gas taxes or vehicle registration fees” (Maciag 2017). This implies that the reliance on parking- and enforcement-related revenues will impact how much a city's budget will be affected by the shift to AVs. 
There have been a handful of policy guides that have been distributed in the last few years. Glus et al's (2017) “Driverless Future: A Policy Roadmap for City Leaders" provides an overview of how cities may shift over the coming decades as a result of AVs and provides recommendations on how cities might plan for these changes. They state that "Cities have a window of opportunity to shape how the autonomous vehicle is used and must act now to define policies that minimize risks and maximize the benefits of driverless technology" (Glus et al. 2017, 2). And while the authors provide a range of recommendations, they only briefly mention the financial impacts of AVs. Fagnant and Kockelman's (2015) study looks at "traffic safety, congestion, and travel behaviors," and while they suggest coming changes to costs and revenues for local governments' budgets, they offer little beyond demonstrating a need for planning and research. Lewis et al. (2017) provides a roadmap for leaders at all levels of U.S. government, but only briefly addresses changes in costs and revenues and does not provide the level of detail needed to be actionable by local leaders. Connery (2016) provides an overview of the impacts of AVs on the municipal bond market, with a focus on the investment risks of General Obligation (GO) bonds related to AVs. The National League of Cities (2017) issued a local government "policy preparation guide" that provides some guidance to cities on preparing for autonomous vehicles. The report provides an overview of AV technology and answers some common questions for cities on that technology. The guide calls for proactive policies by cities and coordination across jurisdictional boundaries - particularly using MPOs (metropolitan planning organizations) to coordinate regionally. Similar to other reports, the NLC only offers a broad sense that cities need to plan for investments and that changes to expenditures and revenues are coming, but offers little specific advice or insight on where within the budget these changes may happen. The City of Seattle issued its own guide, called the "New Mobility Playbook," which indicated a need to diversify revenue sources to respond to AVs becoming commonplace (Seattle Department of Transportation 2017). In this report the city laid out a number of next steps that they will take to get prepared for all types of new mobility that are hitting the streets, including AVs. Seattle's work makes it clear they are aware change is happening, but again the magnitude of change is not projected. Public officials nationwide need to also be aware that AVs will impact both sides of their budget (expenditures and revenues). But, as of yet, the literature provides very limited insight into how to start fiscal and budget planning for AVs.

This section of the report provides some of the first evidence of the impact of TNCs on city budgets and, in turn, some of the first estimates of how AVs might affect budgets. We use the City of Seattle as a leading case in exploring these questions. The results of the paper show that there remains a tremendous amount of uncertainty in how TNCs are affecting city parking, and, consequently, it remains difficult to extrapolate precisely how an AV might change behavior in similar (or different) ways. The evidence from this study does show that as the number of trips taken on TNCs increases beyond the highest levels of ridership that we are seeing today, all else constant, that parking revenue will to decline. The forecast in this report suggests that revenues have already begun to decline, but average TNC use is still low compared to future estimates thus the impact remains very small. With growth rates of ridership increasing, on average, about 20 percent month over month in the five years of this study, it may not take as long to reach a very substantial impact on parking revenue as many think (see Figure 12 in Section 2 of the report for details on growth rates).

Secondly, the impact on parking appears to be highly variable across the city of Seattle. Neighborhoods with high parking revenue today, South Lake Union or Uptown, for example, are 
expected to see much larger swings downward in predicted levels of revenue than areas with less current revenue. And finally, the effects of TNCs may be largely dependent on whether or not someone is being picked up or dropped off. More pick-ups are predicted to decrease revenue while increasing levels of drop-offs are expected to potentially increase revenue.

The remainder of this section of the report is arranged as follows. First, it will propose several questions that guide the research in this report. Next, it will provide an overview of the pertinent literature surrounding TNCs, AVs, and parking. Third, it will provide an overview of the data used in the project and the methods used in the investigation. And finally, it will provide a discussion of the results from the analysis, followed up with a conclusion of the findings.

\subsection{LITERATURE REVIEW}

As Shoup (2017) has detailed, even free parking is far from free. Most parking in the city of Seattle, the city of analysis in this report, is free from direct fees to the user. Parking on most streets around the city is free, at least to those who live there, and often even free to others for a certain number of hours each day.

The actual cost of a single surface parking space can go from nearly zero to more than $\$ 100,000$ (Shoup 2011). While spaces in parking structures range much more widely, the prices can be estimated even without knowing the price of the land beneath them. Though these are not the prices the public typically pays for the use of these spaces. Shoup $(2011,185)$ has estimated that each space in a parking structure costs \$127 each month, and this estimates largely ignores the social and opportunity costs of parking, which would roughly double that amount. The cost to pay debt service and operations/maintenance for each space is not what the public pays for those spaces, as that number is often quite a bit higher. A quick scan of current monthly rates for parking in Seattle would have a user paying from \$190 to more than \$300 per month to have a reserved spot in similar areas to where on-street parking is being metered by the city, though rates do vary widely. The national average, per Shoup (2011), of what a parking lot (public or private) would need to charge to break even would be about \$150/month. For localities where land values are less than $\$ 30 /$ square foot, the cost of surface lots becomes desirable because the cost of garages requires a payback higher than the amount they would be able to receive in income in those lower-rent areas. However, nationwide many cities and employers subsidize parking, making it cheaper to park than the cost of the space would require without the subsidy.

Gutman's (2018) investigation of new garage parking in and around the Seattle metro region shows new construction costs of parking spaces close to $\$ 50,000$ per spot. Based on the replacement cost of parking spaces, Scharnhorst $(2018,21)$ has estimated that the "per-car cost of parking for the 435,000 cars in Seattle is \$82,281.” On-street parking accounts for approximately one-third of all parking spaces in the city, while the rest are private garages, surface lots, and driveways. There are about 1.6 million parking spaces in Seattle-this accounts for about five parking spaces per household and nearly 30 parking spaces per acre, on average, throughout the city. This figure is more similar to a far less dense Des Moines, Iowa, (which has fewer parking spaces per acre than Seattle) than it is to the more densely populated East Coast 
cities of New York and Philadelphia (Scharnhorst 2018). This finding indicates that parking, in all of its forms, is ample in Seattle ${ }^{1}$.

Despite Shoup's (2017) study of free parking and its effects on land use, we still know little about how parking policy decisions are made. Shoup’s (2017) polemic on parking describes a process and set of policies based on path dependence without a rational basis other than "that's just how we've always done it” reasoning. With the advent of off-street parking in the 1930s "urban planners began to assume that most people would travel everywhere by car, park on-site while they worked, shopped, or dined, and then drive on to their next destination" (Shoup 2017, 2). This meant more drivers, more cars, and more congestion. Today " 87 percent of all trips in the U.S. are now made by personal motor vehicles, and only 1.5 percent by public transit" (Shoup 2017, 2), but with the advent of AVs that needed space for on- and off-street parking will be diminished. By requiring parking on-street and off-street, the cost of parking gets passed on to everyone with higher cost of goods and services, because of higher building costs, and less public space because the public rights-of-way are devoted car storage.

The level of uncertainty that planners have when it comes to determining the number of parking spaces needed is quite astonishing. Rates of peak demand vary widely from one office tower to another, one residential building to another, or one commercial space to another. This has resulted in city requirements erring on the side of way too much (free) parking, rather than using any localized analysis or market mechanisms. Excess in parking permeates U.S. society, inducing demand for car trips, pollution, and congestion. When the focus shifts to on-street parking, most smart policies that cities have are not set "to gouge drivers or to maximize revenue. Instead, the right price for curb parking is the lowest price that will avoid shortages” (Shoup 2017, 303). The "best" rate of occupancy should not exceed 85 percent, which will allow for a free space on every block and reduces searching cost, congestion, and, ultimately, CO2 emissions (Shoup 2017).

However, as more city residents use TNCs to get around the need for parking should, hypothetically, decline. Today, however, the vast majority of trips-whether for commuting or for other types - still occur in personal vehicles, and most of those are single occupancy. AVs have the potential to dramatically lower the cost of trips provided by TNCs or services like Google's Waymo. As Clark and Lewis (2018) and Maciag (2017) have noted, the collapse of parking revenue because of AVs is coming, though we are just not yet sure when that day will be. Some estimates of AV adoption would predict that in 20 years the modal transportation choice would be in an autonomous and shared ride-hailing-service (Lyft without a driver). This gives cities some time to adjust. What happens if the modal choice shift starts to impact transportation habits in five or 10 years to the extent that on-street and parking garage revenues drop so significantly that they are no longer sustainable sources of revenue? It should be noted before moving on that the shift from personally owned single-occupancy vehicles to a scenario in which mobility is shared, people largely do not personally own their own vehicle, and vehicles that are AV controlled has an uncertain path. It is clear that AVs will be on the road in the next five to seven years in larger numbers, but it is harder to know how quickly, if at all, the US population will shift from having ownership of cars to sharing cars with others in that future and

\footnotetext{
${ }^{1}$ These spots are not always free of charge or within feet of the destination, which gives the perception to some that parking is scarce in Seattle. This is by no means a Seattle phenomenon; it is seen around the U.S.
} 
beyond. From a planning and congestion standpoint, government officials are now commonly expressing a desire for shared vehicles to reduce congestion from vehicles that no longer need to park. As a consequence, this section of the report seeks to examine a scenario in which I assume, to an extent, that people will use AVs as a mobility service rather than as personally owned vehicles. In the following sections, I discuss the data and methods I use to answer some of these pressing questions.

\subsection{METHODS AND DATA}

\subsubsection{Methods}

In the initial stages of data construction, ArcGIS mapping was used to spatially join datasets that were geographically-based. Once data were spatially joined and the data are collapsed, statistical analysis was used. There is one primary dependent variable, parking revenue. A complete description of the specific unit of analysis is provided in the data section below. Initial tests indicate that our data are not normally distributed in their original format and a log-transformed was used to allow for an unbiased estimation. Using ordinary least squared (OLS) regression models, I am able to forecast on-street parking revenue as a function of the covariates. More than one model is used to estimate and forecast parking revenue to allow for different variations in the ways in which the relationship between TNC ridership data and the dependent variable is explored. Robust standard errors are used in all models because post-estimation tests revealed the potential presence of heteroskedasticity. The figures used throughout this section of the report show dollar figures instead of the log-transformed figures. Marginal effects were calculated for each of the relationships we seek to explore, then the predicted log values were exponentiated which provides a geometric mean rather than an arithmetic mean value for the predicted values.

\subsubsection{Data Sources and Variables}

The data used in this project come from a variety of sources. The time period the study covers is from January 2012 to the end of December 2016. The 2012 start time was chosen because this is when Uber began operations in the City of Seattle and end time is limited by when Uber has provided trip data for this study. Lyft began operations in Seattle in 2013, and are added to Uber trip data at that time.

Seattle Department of Transportation (SDOT) Data: SDOT provided two datasets used in the project. The first data are transaction-level data for all on-street parking in the city. These data record each parking transaction during the study period-including the location of the transaction, the number of minutes purchased and the cost of those minutes. The second dataset from SDOT is block occupancy by the minute during the study period. These data were collapsed to (or summed up to) the Census Tract they are located in using ArcGIS and Stata. Further transformations of the entire dataset are explained below. From these data, I have calculated the revenue Tract revenue for each unit of observation (details on specifications of the units are below). These data serve as the dependent variable in the two models in section 1 . In both instances, I use the natural log of the total parking revenue because these data are skewed. I am also able to estimate parking occupancy at the Tract level from the occupancy dataset. This 
variable is the median occupancy rate for the entire Tract, for the time period in question. It is expected that a neighborhood with higher occupancy could create a situation in which people might be more likely to see alternative transportation modes (TNC, public transportation or active transportation), but in the short-term would lead to higher revenue because more of the available spaces are generating revenue. And finally, I estimate the average rate paid per hour by dividing the total revenue generated by the total number of hours paid for in the Tract. While this calculation will include some inaccuracy, as people can pay for more meter time than they use or pay for less than they actually use, it is assumed that this patter of over/underpayment will be evenly distributed across all parking areas. Rates are adjusted by the city periodically, going both up and down depending on a city policy that calls for particular occupancy levels to be maintained. It would be expected that higher average hourly rate would be positively related to higher parking revenue.

Each parking meter in the city is located in a particular city neighborhood. In the model, we control for these city defined neighborhoods as a way to control for non-measured or nonobserved heterogeneity across the city's neighborhoods. In Models 1 and 2 I have excluded the coefficients associated with the 19 neighborhoods for the sake of parsimony. Varying effects of the neighborhoods can be seen in Figure 2.

TNC Data: Lyft provided Census Tract-level trip data. The number of pick-ups, drop-offs, and the total number of both kinds of trips were extracted from these data. These data are available from January 2013 to December 2017, though we only use data up to the end of 2016. Uber provided Census Tract-level trip count data-including the number of pick-ups in a Tract (ending in another Tract), the number of drop-offs (starting in another Tract), and the number of trips that start and end in the same Tract. The two models in this section use different variants of TNC trips. In Model 1, I use the total number of trips (pick-ups and drop-offs combined) in a Tract during the specified time period. In Model 2, I used three separate figures that make up total trips separately: the number of pick-ups in a Tract (ending in another Tract), the number of drop-offs (starting in another Tract), and the number of trips that start and end in the same Tract. A priori it would be expected that more total TNC trips would decrease parking revenue, because it is assumed that these travelers no longer need to park, thus freeing up a parking spot, and decreasing revenue. The disaggregated trip counts in Model 2, a priori, should behave somewhat differently. I would expect that drop-offs and same Tract trips would have a negative impact on revenue because one might assume that they would have driven to the neighborhood otherwise, but now do not require their own vehicle nor pay for parking. Pick-ups would likely have little impact on the origin Tract, but instead, have a parking revenue impact on the Tract where they terminate.

Census Bureau American Community (ACS) Survey Data: ACS data used in this study are car ownership, population density, and median household income by Census Tract. The five-year averages were used for all study years. It is expected that areas with higher car ownership might have a higher demand for parking, thus a higher parking revenue. This may be because there are more drivers, but also because more "free" on-street spots are taken by residents, thus pushing visitors toward paid on-street parking, increasing revenue. A greater population density would be expected to create greater transportation demands and consequently more parking revenue. And finally, household income is likely to be negatively related to on-street parking revenue because 
the wealthier the neighborhood is, the more likely there are to be off-street parking options for homeowners, thus decreasing demand and parking revenue.

State of Washington Data: Beer, wine, and liquor license data were collected from the State of Washington. Each license holder's address in Seattle was geolocated within a Census Tract by year. The variable, as presented in the models, is the aggregate number of establishments with a license in the spatial-temporal form of the data overall. Entertainment driven neighborhoods draw more people to those neighborhoods by all means of transportation-thus have a greater demand for parking and could generate more revenue. One way in which to capture which areas have more of these draws is to look at restaurants and bars that serve alcohol as a proxy.

Fuel Price Data: The data on the average cost of all grades of retail gasoline were sourced from the U.S. Energy Information Administration (2019). By controlling for the cost of gasoline a driver might pay, we can account for whether or not it affects how much revenue on-street parking might collect. When gas prices are higher people may be less likely to travel by personal vehicle, thus revenue could go down.

\subsubsection{Data Transformations}

The size of the dataset, primarily the data from SDOT, created challenges in geospatial and statistical analysis. The parking occupancy dataset is approximately 500GB in size. The parking transaction dataset is considerably smaller, but still substantial at roughly 60GB. With these two datasets in use, I chose to collapse the data to more a more manageable size, which allows for quicker computing times and provided for a clearer explanation of the phenomenon without losing a substantial amount of explanatory power or distorting results ${ }^{2}$.

The unit of observation that all data are collapsed to is based on the geography of a Census Tract that has paid on-street parking. For each Tract, there are three observations (morning [8-10], afternoon [11-3], and evening [4-7]) per month for each day of the week that parking fees are assessed (Monday-Saturday). For example, all figures would be summed up to all mornings, on Mondays in the month of January in the year 2015. Thus, observations six days of the week, times three time periods per day, for each month of a study year, or 18 observations per Tract per month. The resulting sample size for the study is 25,150, with 2 percent of observations coming from 2012, and between 20 and 26 percent of the observations coming from each of the other years of the study.

\footnotetext{
${ }^{2}$ In the early stages of the analysis I used quarterly aggregations of parking and TNC data. The magnitude and significance of the effects seen in this report are similar to those using quarterly aggregations. When using a finer level of aggregation, data aggregated to the hour of day and day of the month, the results were, again, similar in size and significance to what is seen in the results found in this report.
} 


\subsection{RESULTS}

In a first-of-its-kind analysis, this section of the report provides a mixed message of how TNCs are impacting on-street parking revenue. The forecasting efforts in this paper potentially provide insight into how AVs might further shape this revenue stream for cities.

The results from Models 1 and 2 can be found in Table 1.1 below. I will first focus on the independent variable of greatest interest-TNC trips. Model 1 includes the combined TNC trip variable -all pick-ups and drop-offs in that unit of observation. In Model 2, the trip variable is split into pick-ups, drop-offs, and same Tract trips separately.

In Model 1 the measure of TNC trips aggregates all pick-ups and drop-offs into one single variable. For each additional trip taken in a Census Tract, all else held constant, we would expect that revenue would decrease by 0.001 percent or about 1 percent for each additional thousand trips. Figure 1.1 and Figure 1.2, below, help to visualize how the effects of TNC trips effect parking revenue, all else equal, over a range of possible trip volumes. The vertical dashed line on Figure 1 represents the average number of trips taken during 2016 during that time of day-these ranged from about 1,200 in the morning to about 2,300 in the evening. The solid vertical line represents the maximum number of trips taken, which ranges from about 6,600 in the mornings to around 15,000 trips in the evening. It should be noted again that these trip figures are aggregations of those time periods for all Mondays, Tuesdays, and so on for each month of the year during the study period. Consequently, interpreting the number of trips as it relates to revenues (also in the same time frame) needs to be taken in that context.

Looking at Figure 1.1, it is apparent that ridership and parking revenue vary from morning to afternoon to evening, thus the amount of revenue collected also varies accordingly. The solid vertical lines in each quadrant of Figure 1.1 represent the maximum observed value of TNC trips in each time block, which means that all information to the right-hand side of these lines represent the average predicted revenue for these times of the day. Thus, looking at these graphs in Figure 1.1, the revenue-TNC relationship to the left of the vertical lines is based on what has been observed, while everything to the right of that vertical line is a forecast of what we might expect in the future as TNC trips double their highest level of ridership today. It should be noted that these graphs represent what revenue would look like if no policy action is taken to change parking rates. All of these graphs are estimated with the average cost of parking and occupancy fixed at their mean values. Seattle, like many cities around the country, is frequently adjusting parking rates to achieve an optimal parking occupancy rate (between 70-85 percent) ${ }^{3}$. As more trips using TNCs occur, occupancy would likely go down and the city would adjust rates in response, which would in turn further affect these total revenue figures.

Figure 1.2 shows how increasing levels of TNC use effect parking revenue by neighborhood. The neighborhoods included in the study are only those that have paid on-street parking, thus excluding large parts of the city that are largely residential. These graphs largely show that

\footnotetext{
${ }^{3}$ Seattle seeks to maintain an occupancy rate between 70 and 85 percent (Baruchman 2018)—-the 85 percent occupancy rate is what Shoup (2017) has outlined as an ideal occupancy rate, as it will leave at least one free spot on a block to reduce cruising, congestion, and $\mathrm{CO} 2$ emissions from those activity levels.
} 
neighborhoods with higher levels of on-street parking revenue will see larger declines in revenue moving forward.

In Model 2, the TNC trip variable is disaggregated by pick-ups (going to another Tract), dropoffs (coming from another Tract) and trips that start and finish in the same Tract. Pick-ups decrease parking revenue, drop-offs appear to increase them, and same Tract trips decrease them. For each additional pick-up, on-street parking revenue drops by 0.013 percent —or 13 percent for every 1,000 additional trips. For each additional drop-off, on-street parking revenue increases by 0.020 percent — or 20 percent for every 1,000 additional trips. For each additional trip staying in the same Tract, on-street parking revenue decreases by 0.27 percent—or about 270 percent for every 1,000 additional trips. All three of the trip variables are calculated for the mean number of pick-ups, drop-offs, or same Tract trips, rather than across a range of values. However, if we look at Figure 1.3, which includes calculations beyond just the mean value, it is possible to begin to see how the effects of the number of TNC trips as they get larger and larger-similar to what was seen in Figure 1.1 and Figure 1.2. It is important to note that these three figures are not on the same y-axis scale; the drop-off scale covers a much larger and higher range of dollar values. The vertical line on both of the graphs within Figure 1.3 indicates the cut-off point of what is observed (to the left of the line) and what is predicted (to the right of the line). And while we have observed rates of trips up to those vertical lines, the mean rate is 419 for pick-up, 413 for drop-off, and only seven for same Tract trips.

As we look more closely at Figure 1.3, it is possible to see that as the number of trips increases beyond what is observed. First, given the small number of average same Tract trips-averaging only seven in each time period-it would seem as though these shorter trips are not likely to play a big role in the volume of trips and how revenue is impacted, even with such a dramatic decline in revenue with each additional trip. Drop-offs seem to be the largest dollar value impact on revenue. It should be noted that as we interpret these predicted revenue figures over the range of values, that the other trip variables are held at their means - this is not measuring dynamic growth of both pick-ups and drop-offs. This is a clear advantage of viewing all trips similarly, as is done in Model 1.

Cost to Park: The relationship between the average amount paid to park (on-street only) is similar in both Models 1 and 2. When the rate increases by $\$ 1$, we would expect that parking revenue would go up by about 34.5 percent. This finding holds occupancy constant at its mean, thus the actual increase in parking revenue is not dynamic and may not accurately reflect behavior change.

Occupancy Rate: When the rate of on-street parking increases the results of both models would indicate that we would expect to see about a 3 percent increase in revenue for every 1 percent increase in the occupancy rate. This increased revenue in both models is calculated with the number of TNC trips set at the mean value, 828 total trips or about 419 pick-ups, 413 drop-offs and 7 same Tract trips. In Figure 1.4, I have estimated changes in revenue based on a number of different possible scenarios. The curves illustrating the relationship between parking occupancy and parking revenue are all similarly sloped and changing over the range of values. This estimate is based on no change in the parking cost for drivers. It is clear from the City of Seattle policy that they would like to change prices if they saw occupancy going down, which is what we might 
expect in the long term with more trips that do not require parking. Again, Seattle's parking policy does not seek to maximize revenue, but rather is a policy that is focusing on the utility of parking as a public good by seeking to maximize occupancy.

Beer \& Wine Selling Establishments: As the number of establishments that sell beer and wine within a Census Tract increase, revenue for on-street parking increases as well. Each additional establishment in a Tract increases parking revenue by about one percent. Figure 1.5 provides a visual of this relationship.

Median Household Income: For each \$1,000 increase in median household income in a Census Tract the results of Models 1 and 2 show an approximate one percent decrease in parking revenue. Figure 1.6 shows the relationship graphically across the range of possible observed values of household income. This finding demonstrates a potential equity issue for on-street parking revenue, as wealthier neighborhoods appear to generate less revenue (and thus charge those residents less) than poorer neighborhoods.

Population Density: For each additional 1,000 people per square mile, we can expect to see an increase in on-street parking revenue of roughly 0.3 percent in both models. Figure 1.7 shows this relationship graphically.

Average Cost Per Gallon of Gasoline: For each dollar increase in gasoline price, the revenue for on-street parking decreases by more than five percent. Figure 1.8 shows this relationship graphically over the range of observed gasoline prices during the study period. This effect becomes less prominent as more and more vehicles are powered by electric power rather than gasoline/Diesel. While the number of electric-powered vehicles still only makes a small fraction of total VMT, the growth of this fuel source is growing rapidly-and will be likely be accelerated in the rollout of AVs. 
Table 1.1: Ordinary Least Squared Models 1 and 2

\begin{tabular}{|c|c|c|c|c|}
\hline VARIABLES & $\begin{array}{c}\text { (1) } \\
\text { Parking } \\
\text { Revenue--all } \\
\text { trips }\end{array}$ & se & \begin{tabular}{|c|} 
(2) \\
Parking \\
Revenue--by \\
pick-up or \\
drop-off \\
\end{tabular} & se \\
\hline All pickups and dropoffs & $-0.00001 * *$ & {$[0.00000]$} & & \\
\hline TNC Pickups & & & $-0.00013 * *$ & {$[0.00001]$} \\
\hline TNC Dropoffs & & & $0.00020 * *$ & {$[0.00001]$} \\
\hline TNC Pickup/Dropoffs Same Tract & & & $-0.00270 * *$ & {$[0.00026]$} \\
\hline Average cost to park on-steet per hour & $0.34583 * *$ & {$[0.01424]$} & $0.34605 * *$ & {$[0.01411]$} \\
\hline On-Street Parking Median Occupancy Rate & $0.02935^{* *}$ & {$[0.00032]$} & $0.02844 * *$ & {$[0.00033]$} \\
\hline Paid Parking Spaces in Tract (in 100s) & $0.10840 * *$ & {$[0.00292]$} & $0.11286^{* *}$ & {$[0.00296]$} \\
\hline Number of Vehicles (Cars, Trucks, Vans) in 100s & $-0.04257 * *$ & {$[0.00157]$} & $-0.04145 * *$ & {$[0.00157]$} \\
\hline Number of Beer/Wine selling establishments & $0.01389 * *$ & {$[0.00030]$} & $0.01388 * *$ & {$[0.00030]$} \\
\hline Median Household Income in $\$ 1000$ s & $-0.01066^{* *}$ & {$[0.00042]$} & $-0.01091 * *$ & {$[0.00042]$} \\
\hline Population Density (1000 people per sq mile) & $-0.00299 * *$ & {$[0.00052]$} & $-0.00330 * *$ & {$[0.00052]$} \\
\hline Average cost per gallon of Gasoline & $-0.05114^{* *}$ & {$[0.01199]$} & $-0.04975^{* *}$ & {$[0.01190]$} \\
\hline \multicolumn{5}{|l|}{ Time of Day (Omitted Group: Morning [8-10am]) } \\
\hline Afternoon (11-3) & $0.30255^{* *}$ & {$[0.01322]$} & $0.32339 * *$ & {$[0.01342]$} \\
\hline Evening (4-7) & $-0.82170 * *$ & {$[0.01495]$} & $-0.80256^{* *}$ & {$[0.01534]$} \\
\hline \multicolumn{5}{|l|}{$\begin{array}{l}\text { Day of the Week (Omitted Group: Monday; no paid } \\
\text { parking S undays) }\end{array}$} \\
\hline Tuesday & $0.08936^{* *}$ & {$[0.01283]$} & $0.09102 * *$ & {$[0.01276]$} \\
\hline Wednes day & $0.07739 * *$ & {$[0.01282]$} & $0.07941 * *$ & {$[0.01274]$} \\
\hline Thursday & $0.04476^{* *}$ & {$[0.01273]$} & $0.04743 * *$ & {$[0.01265]$} \\
\hline Friday & $0.06938 * *$ & {$[0.01284]$} & $0.06574 * *$ & [0.01279] \\
\hline Saturday & $0.03882 * *$ & {$[0.01229]$} & $0.03340 * *$ & {$[0.01223]$} \\
\hline Year Trend & $0.04840 * *$ & {$[0.00704]$} & $0.03890 * *$ & {$[0.00724]$} \\
\hline \multicolumn{5}{|l|}{ Neighborhood Controls Included in All Models } \\
\hline Constant & $-91.67747 * *$ & {$[14.21175]$} & $-72.52042 * *$ & {$[14.61317]$} \\
\hline Observations & \multicolumn{2}{|l|}{25,150} & \multicolumn{2}{|l|}{25,150} \\
\hline R-squared & \multicolumn{2}{|l|}{0.88650} & \multicolumn{2}{|l|}{0.88803} \\
\hline
\end{tabular}

Robust standard errors in brackets

** $\mathrm{p}<0.01, * \mathrm{p}<0.05$ 


\section{TNC Trips Effects on Parking Revenue}

With $95 \%$ Confidence Interval
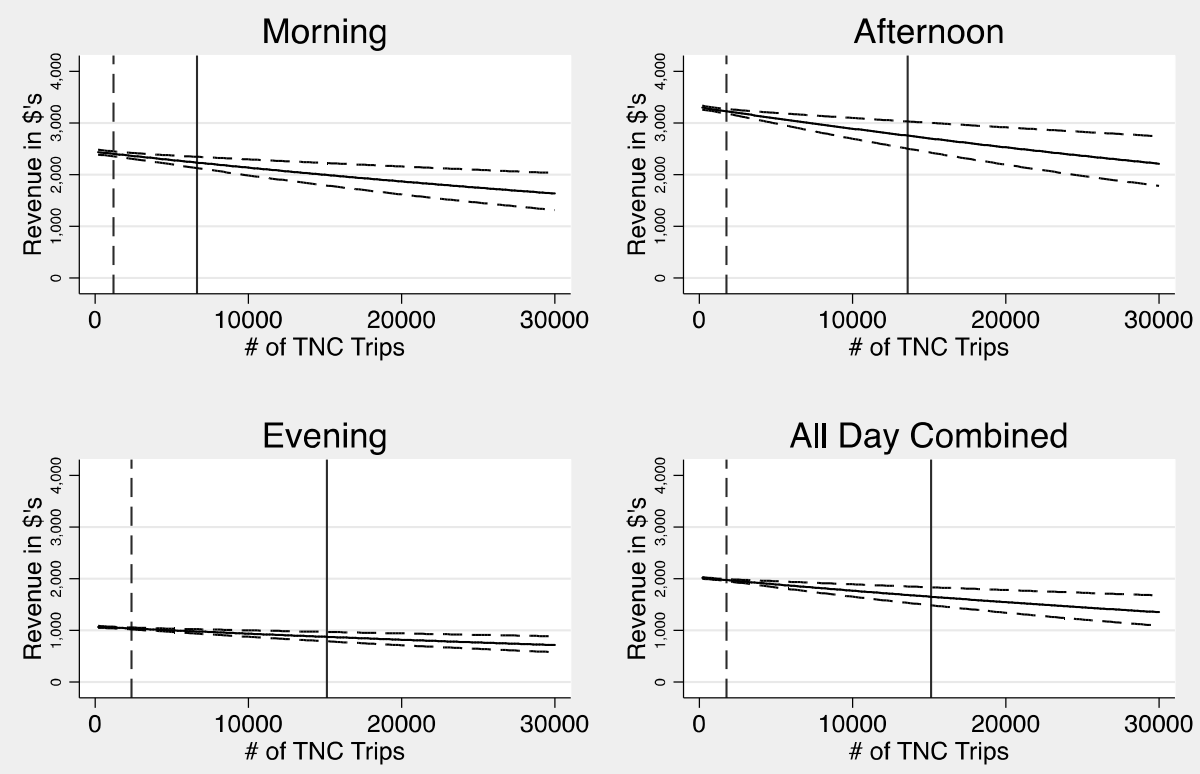

Figure 1.1 


\section{TNC Trips Effects on Parking Revenue--By Neighborhood}

With $95 \%$ Confidence Interval
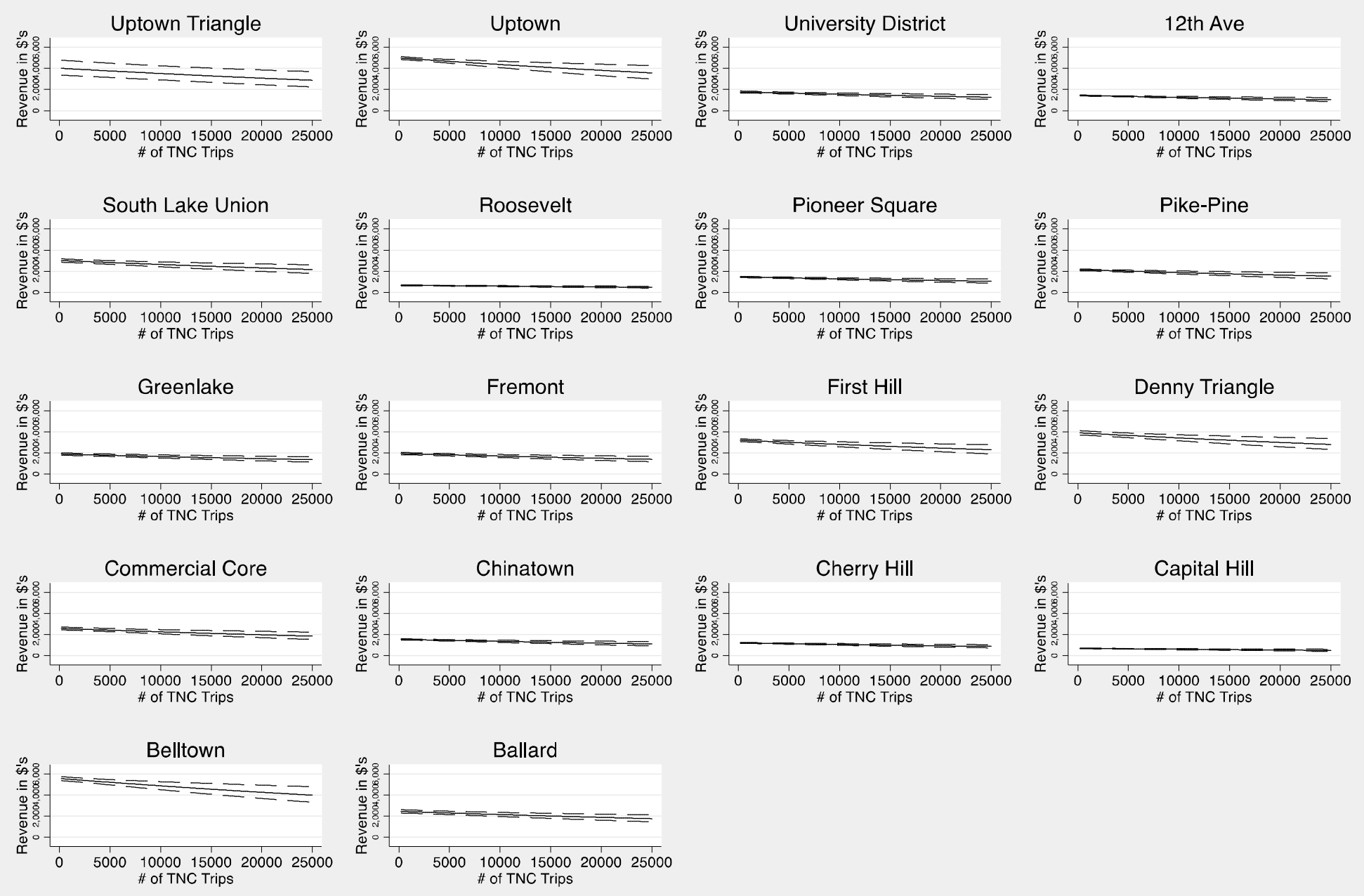

Figure 1.2 
TNC Pick-Up and Drop-Off Effects on Parking Revenue
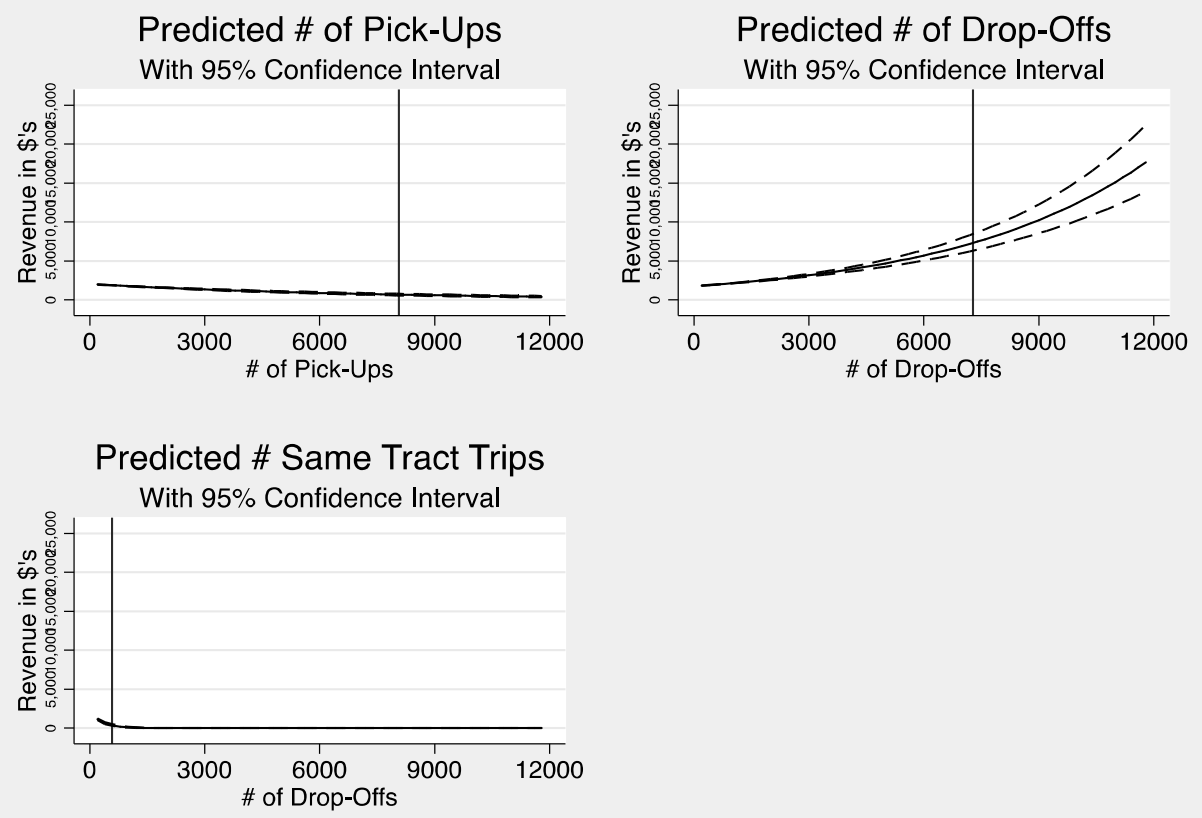

Figure 1.3

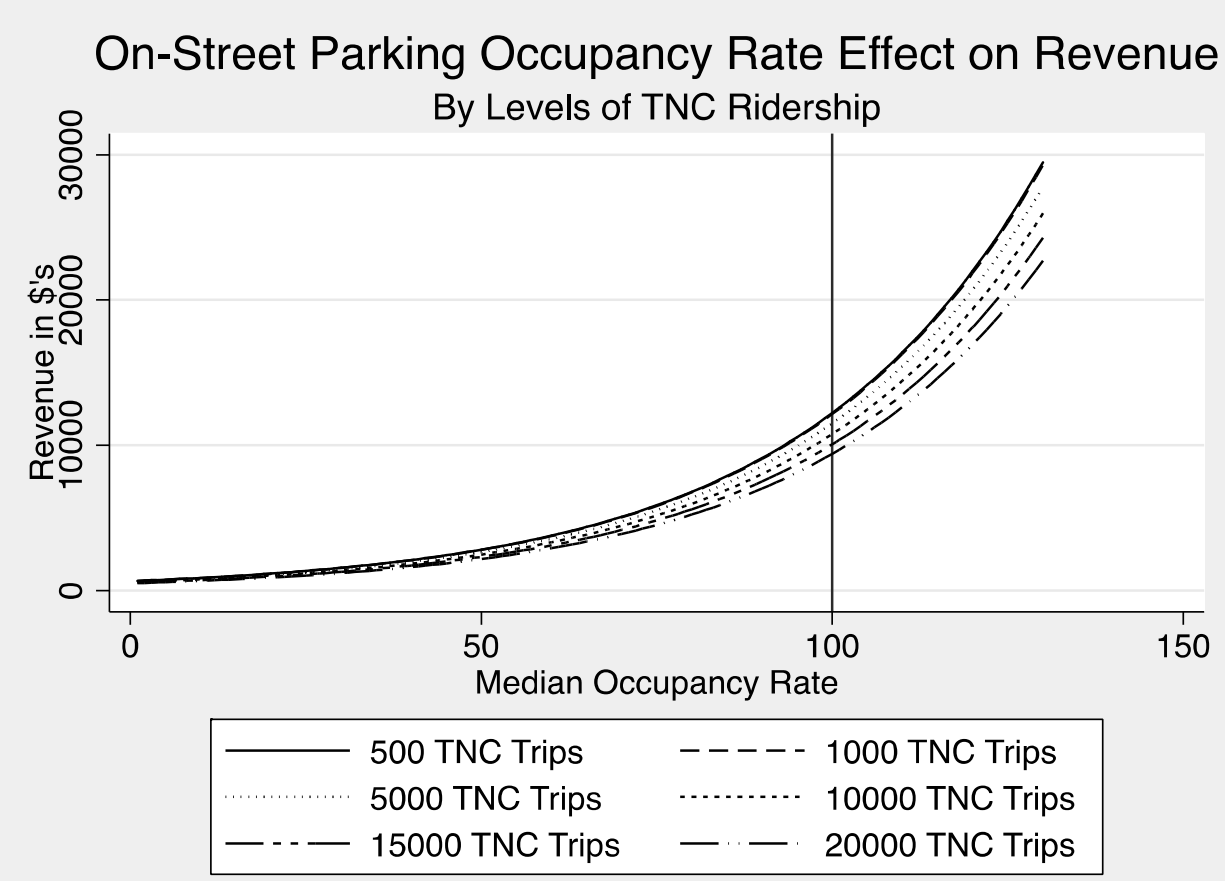

Note: Rate exceed $100 \%$ because people pay for more parking than they use

Figure 1.4 


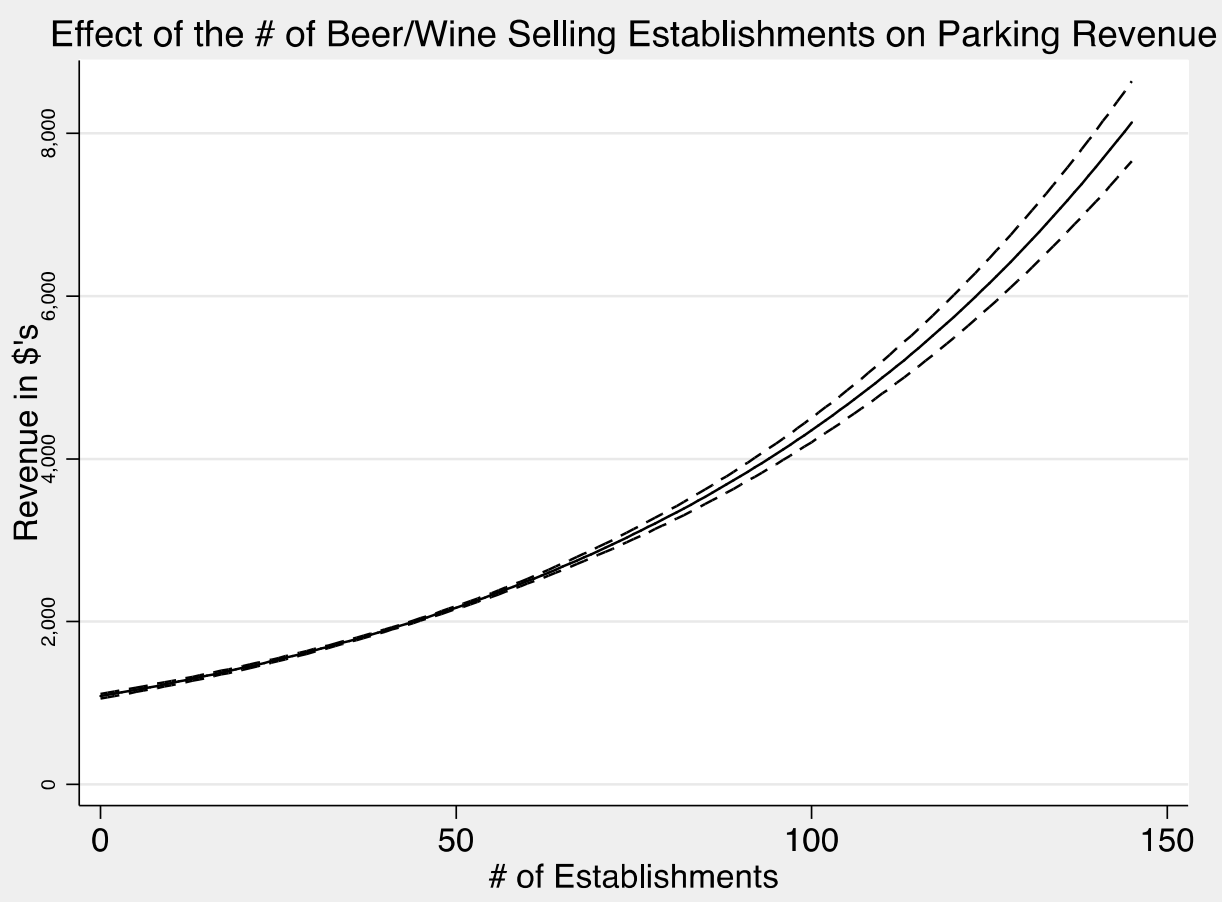

Figure 1.5

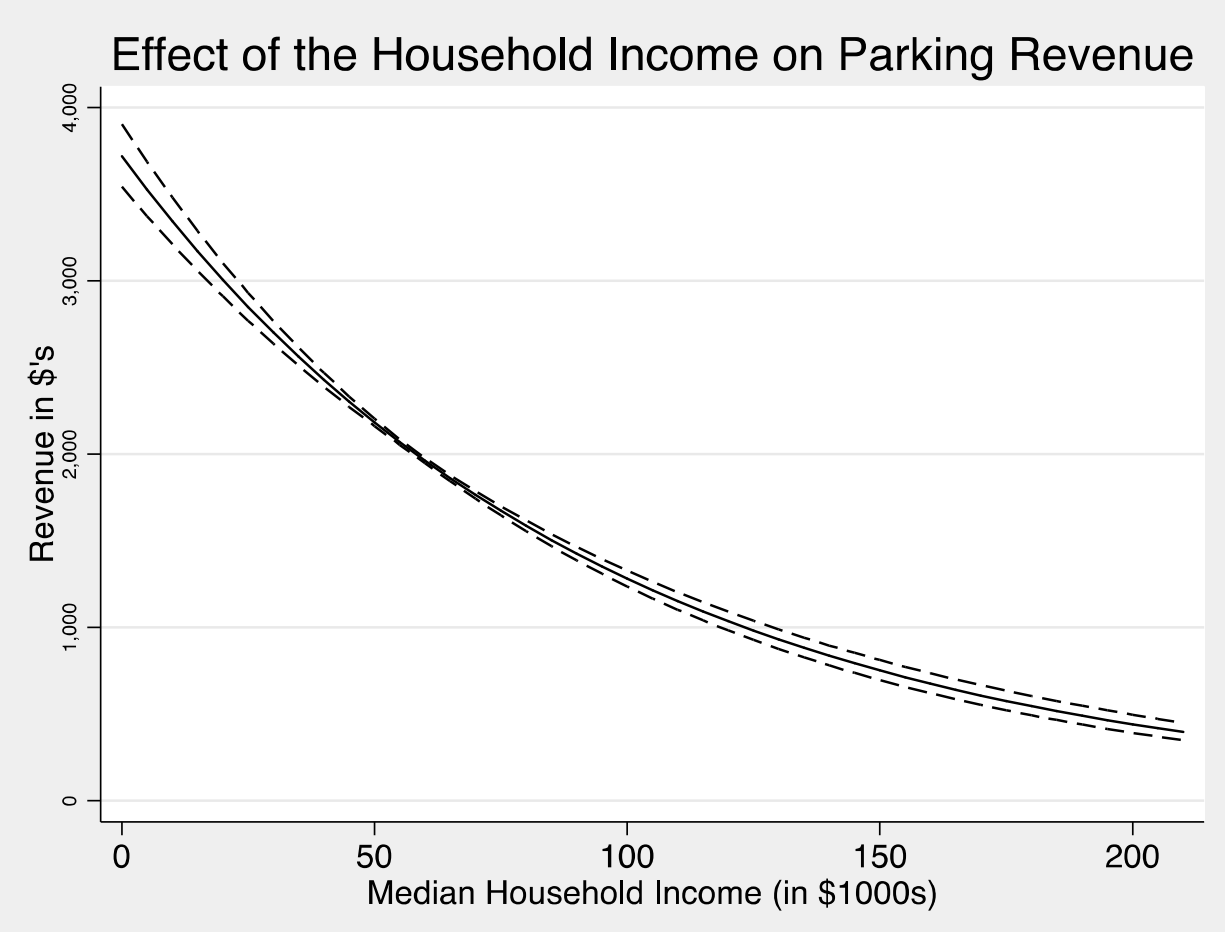

Figure 1.6 


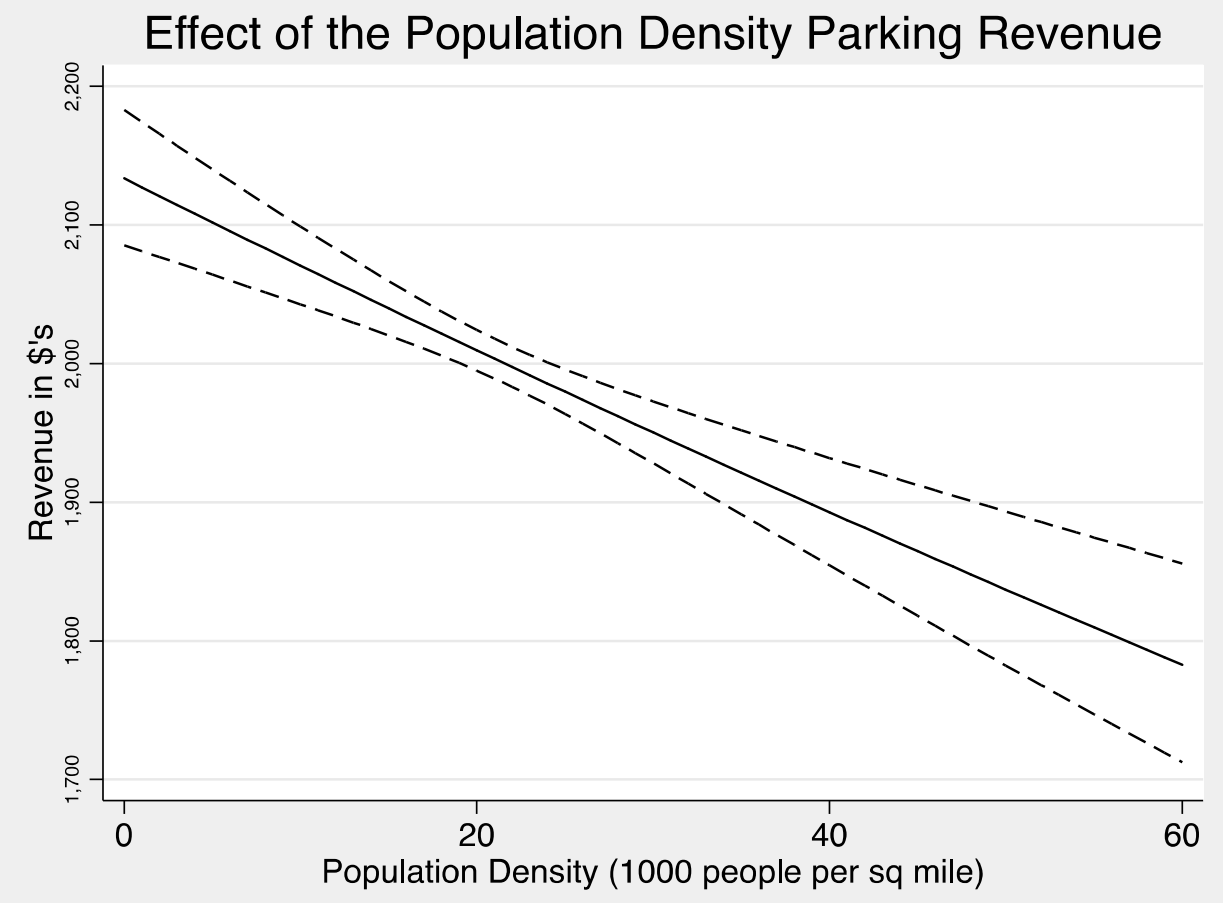

Figure 1.7

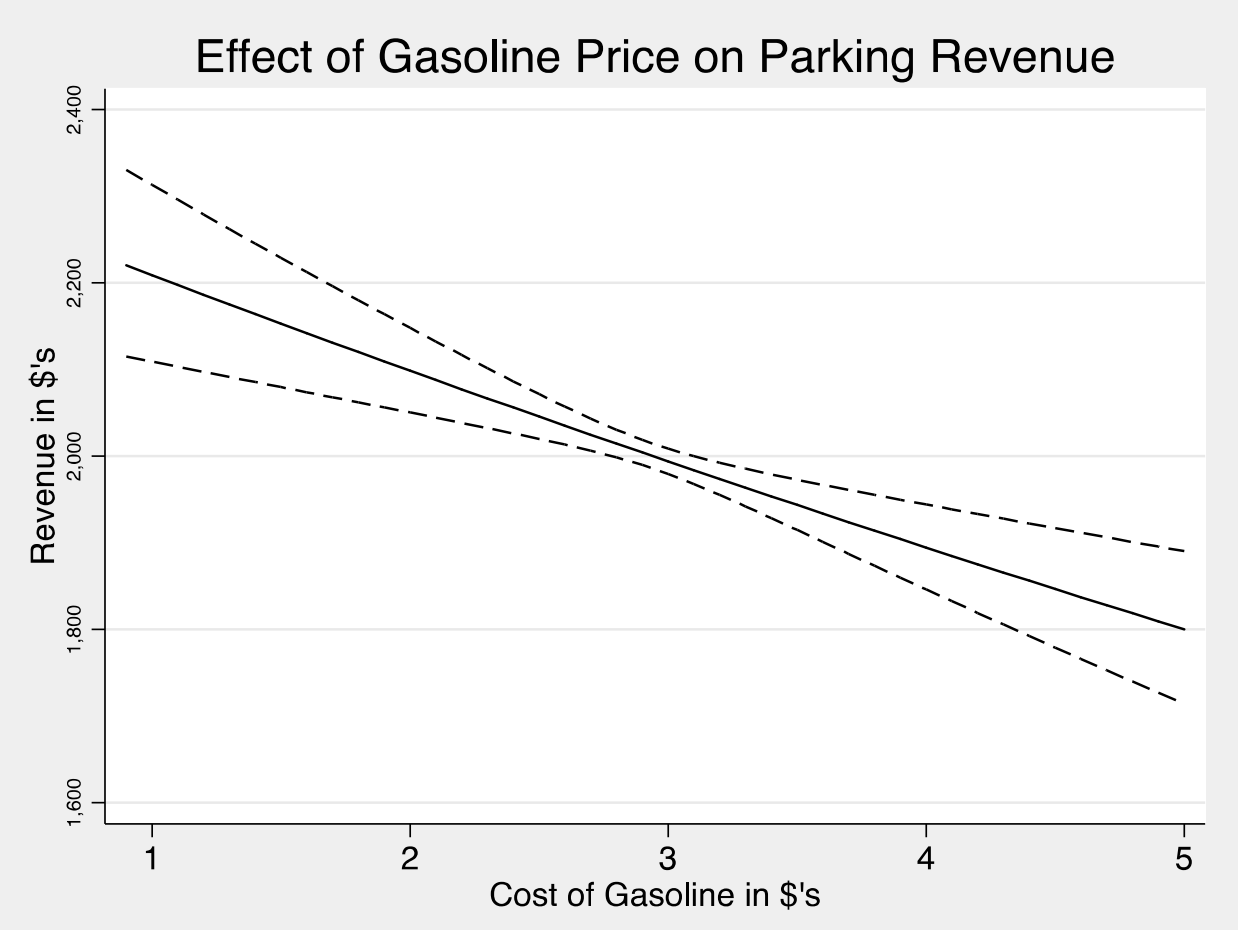

Figure 1.8 


\subsection{DISCUSSION AND CONCLUSION}

The results of the analysis presented in this section of the report should push cities to become more aware of the consequences of doing nothing in the face of the increasing use of TNCs and eventually AVs. While Seattle, like many cities, does not use revenue maximization as the driving force behind how it sets parking rates, it is clear that if they chose to just let their rates ride from here on out that they could see a significant decline in revenue in a very short time. In the fiscal year 2018 budget, parking meter revenue represented a little more than three percent of total general fund revenue-or about \$44 million (City of Seattle, Washington 2018). The share of total general fund revenue that parking generates has remained reasonably constant over the last 5 years.

However, as we look to the unexpected and exponential growth of TNCs in the last decade, cities worldwide were often left behind seemed reactive to what was happen around them. Moving forward cities can plan for some of the changes and be more proactive to shape their cities into what they want them to be, rather than have to shape the city around what a new mode of transportation imposes on them. Cities should consider retaking the public right-of-way used for parking for other uses, eliminating some on-street parking in the future rather than simply trying to optimize on price, for example. They might want to consider optimizing the available number of spaces by removing some spaces from the neighborhood capacity instead, rather than using price as the optimization mechanism.

If a city is to base decision making on the average ridership of TNCs in the last five or six years, things might still appear to be unremarkable. However, the rapid growth of TNCs and the pending introduction of AVs in cities in the next several years could come as a shock if cities do not look at the extreme values of what we are already seeing today. Driving alone, even in Seattle, is still done by the majority of travelers. However, as the cost of TNCs drop with automation, it is very feasible to expect more and more people getting out of their own cars and using shared mobility services_-similar to the phenomenon we are seeing currently with Uber and Lyft.

The results of the models in this section, and the figures that visualize their impact moving forward paint a potentially bleak picture of parking revenue_-assuming no action by cities. Lowering the cost of parking will likely be a result of diminishing demand for parking, which will further erode these parking revenue figures as all estimates in these models assume parking rates are frozen at their average rate today. Future research will need to do a dynamic analysis that assesses the changes in parking rates in response to higher TNC use, and how those changes paired with one another could impact parking revenues.

The prognosis in this report should not be seen as all doom and gloom, however. With decreasing demand for on-street parking and associated revenue, cities are offered an opportunity to rethink what they do with these rights-of-way currently being used as storage for personal vehicles. Clearly, one new or adapted use will necessarily be for pick-up and drop-off zones with more vehicle miles traveled coming from TNC/AV rather than personal vehicles. We discuss the types of alternative uses for these rights-of-way in more detail in Section 2 of this report. 
It is clear that city managers or mayors should not begin the complete dissolution of on-street parking today. This is most substantially seen in the potential differences between results in Models 1 and 2. By examining the different effects of pick-ups and drop-offs on parking revenue, particularly as visualized in Figure 1.3, policy-making becomes a bit muddied. This opposing directional impact, in contrast with a clearer picture from Figure 1, provides limited insight on a viable policy. There still remains a potential that revenue could increase under the new regime of transportation options. I would expect that this wide gap in uncertainty will shrink considerably as more TNC trips are taken in the coming years, providing us with better estimates of higher volumes of trips and as behaviors related to TNC use becomes more clear. 


\subsection{RECLAIMING THE CURB AND DITCHING THE LOT IN AN ERA OF TNCS AND AVS}

This section authored by: Maggie Charles, Kerry Edinger, Kelsey Madsen, Justin Sandoval, and Benjamin Y. Clark ${ }^{4}$.

\subsection{INTRODUCTION}

As cities look at the congestion that is being attributed to TNCs (Schaller 2018) as drivers wait for their riders to get in or out of vehicles, it provides a window into the challenges cities will face once more of the vehicles and the trips taken in them are done using TNC (or eventually AVs). Understanding how parking revenues were affected by TNCs was covered in Section 1 of this report. In Section 2, we move toward a study of how demand for parking might change and how cities can start to focus more on how to better allocate the curb space. The following case studies highlight the efforts of these cities to show the versatility and opportunities associated with transportation planning in the future.

This section of the report will provide a basis of understanding of how on-street parking demand is changing in Seattle and the ways curb space can be reimagined to better accommodate new and changing needs of these public spaces. We will then lay out a number of alternatives that are already being tried in cities around the world to manage curb space and facilitate better flows of traffic.

\subsection{PARKING DEMAND IN SEATTLE}

In Seattle, the average parking occupancy level across our study period is (2012-16) about 40 percent. Which means that on a typical day, at any point during the day, you are not going to have a hard time finding a parking space. The geography we use in which you would find a parking space is far larger than the average driver would hope to have to search for a parking space-an entire Census Tract. This, of course, does not mean people will never circle blocks immediately near their destination searching for parking because this will happen. Rather this figure demonstrates that overall the parking supply is not being fully used.

In this section, we model parking occupancy rather than parking revenue. In Table 2.1, below, we can see two models that use a similar structure to the models in the first section of this report. For information on the data and variables, please refer to that earlier section. In Models 3 and 4 (Table 2) the dependent variable is the natural log of the median occupancy rate for the Census

\footnotetext{
${ }^{4}$ This section of the report was written in collaboration with a team of graduate students in the University of Oregon's Masters of Public Administration (MPA) program as part of their capstone project. The first four authors of this section are the students, and their names are listed in alphabetical order.
} 
Tract. The log is used here rather than the percentage value because the distribution was bimodal and non-normally distributed ${ }^{5}$.

The results in Model 3 and those seen in Figure 2.1 demonstrate the negative relationship between parking occupancy levels and TNC ridership. For each additional TNC trip, a subsequent decrease in parking occupancy will be about 0.012 percent or a decrease of about 12 percent for every 1,000 trips. Figure 2.1 shows how this effect will likely moderate as the increase in TNC trips increases - as the slope becomes flatter. The vertical line represents the highest observed value in the data—at about 15,000 trips in the time measured time period. However, as was noted in the previous section, the average number of trips is actually much lower than that. In 2016, the last year of our study period, the average number of trips was about 1,700 . What this graphic demonstrates is that as we continue to see exponential growth of TNC trips, with no policy change, we could expect to see very dramatic declines in the demand for parking across the city — ultimately nearly no yielding no demand for parking at all once they reach an average about twice that of the current highest observed value of total trips—or about 30,000 . Seattle does frequently take action to assure that rates for on-street parking are matching demand, thus the slope of this curve would likely drop much more slowly.

\footnotetext{
${ }^{5} \mathrm{~A}$ very number was added to the occupancy rate prior to computing the natural log- 0.000000000000001 . This practice is done to avoid all zero values in the occupancy data from being dropped from the analysis. Roughly $25 \%$ of the observations in the data have a value of zero for occupancy.
} 
Table 2.1: Ordinary Least Squared Models 3 and 4

\begin{tabular}{|c|c|c|c|c|}
\hline VARIABLES & $\begin{array}{c}\text { (3) } \\
\text { Oocpancy-All } \\
\text { Trips }\end{array}$ & se & $\begin{array}{c}\text { (4) } \\
\text { Ocpancy-Trip } \\
\text { Types }\end{array}$ & se \\
\hline All pickups and dropoffs & $-0.000118 * *$ & {$[0.000021]$} & & \\
\hline TNC Pickups & & & $-0.000381 * *$ & {$[0.000051]$} \\
\hline TNC Dropoffs & & & $0.000253^{* *}$ & {$[0.000039]$} \\
\hline TNC Pickup/Dropoffs Same Tract & & & $-0.003432 * *$ & {$[0.000984]$} \\
\hline Average cost to park on-steet per hour & $-0.465506^{* *}$ & {$[0.071195]$} & $-0.459573 * *$ & {$[0.070919]$} \\
\hline Paid Parking Spaces in Tract (in 100s) & $-0.147947 * *$ & {$[0.016472]$} & $-0.140104 * *$ & {$[0.016489]$} \\
\hline Number of Vehicles (Cars, Trucks, Vans) in 100 s & $0.026793 * *$ & {$[0.008720]$} & $0.027893 * *$ & {$[0.008735]$} \\
\hline Number of Beer/Wine selling establishments & $0.036314^{* *}$ & {$[0.002388]$} & $0.036074 * *$ & {$[0.002392]$} \\
\hline Median Household Income in $\$ 1000$ s & -0.003361 & {$[0.003062]$} & -0.003554 & {$[0.003046]$} \\
\hline Population Density (1000 people per sq mile) & $-0.012599 * *$ & {$[0.002846]$} & $-0.012678 * *$ & {$[0.002801]$} \\
\hline Average cost per gallon of Gasoline & $0.391231^{* *}$ & {$[0.070009]$} & $0.389836^{* *}$ & {$[0.069876]$} \\
\hline \multicolumn{5}{|l|}{ Time of Day (Omitted Group: Morning [8-10am]) } \\
\hline Afternoon (11-3) & $2.244746^{* *}$ & {$[0.069177]$} & $2.238892 * *$ & {$[0.069116]$} \\
\hline Evening (4-7) & $2.289310^{* *}$ & {$[0.072623]$} & $2.281382 * *$ & {$[0.073242]$} \\
\hline \multicolumn{5}{|l|}{$\begin{array}{l}\text { Day of the Week (Omitted Group: Monday; no paid } \\
\text { parking Sundays) }\end{array}$} \\
\hline Tuesday & 0.073189 & {$[0.056089]$} & 0.073110 & {$[0.056111]$} \\
\hline Wednesday & 0.080739 & {$[0.058004]$} & 0.080543 & {$[0.058004]$} \\
\hline Thursday & $0.171349 * *$ & {$[0.053539]$} & $0.171684 * *$ & {$[0.053695]$} \\
\hline Friday & $0.230287^{* *}$ & {$[0.054097]$} & $0.219924 * *$ & {$[0.054727]$} \\
\hline Saturday & $-1.136219 * *$ & {$[0.107071]$} & $-1.147361 * *$ & {$[0.108138]$} \\
\hline Year Trend & $0.420996^{* *}$ & {$[0.050348]$} & $0.409413^{* *}$ & {$[0.053522]$} \\
\hline \multicolumn{5}{|l|}{ Neighborhood Controls Included in All Models } \\
\hline Constant & $-846.832764^{* *}$ & {$[101.596909]$} & $-823.508301^{* *}$ & [107.981720] \\
\hline Observations & 25,150 & & 25,150 & \\
\hline R-squared & 0.151694 & & 0.152639 & \\
\hline $\begin{array}{l}\text { Robust standard errors in brackets } \\
* * \mathrm{p}<0.01, * \mathrm{p}<0.05\end{array}$ & & & & \\
\hline
\end{tabular}

Figure 2.2 shows how these results would vary from neighborhood to neighborhood. These findings suggest that cities will need to be assessing parking rates and planning for curb space redevelopment or reuse differently in each neighborhood. The Capitol Hill neighborhood in Seattle, for example, could see the sharpest drop in demand with increased TNC use. Currently, the estimated demand for parking is exceeding the actual supply in this neighborhood. Over time the model and graphic representation of the model (Figure 2.2) shows that a very dramatic drop in demand will happen without changes to the policy. Other neighborhoods have much flatter slopes and might not need to require some of the more proactive policy actions by the city.

Looking now to Model 4, we can see how the impacts of pick-ups and same Tract trips move in the opposite direction of drop-offs. This same pattern of effects on occupancy was seen when we examined parking revenue as well. The decreases in occupancy levels in pick-ups and same Tract trips are much swifter than drop-offs. As was the case in the previous section, these results 
with trip types split, make interpretations difficult to interpret given the other trip variables are held constant when each trip type is evaluated by itself-drop-offs and same Tract trips are held at their mean when we evaluate pick-ups. The non-dynamic nature of this analysis should lead us to read very little into the results seen in Figure 2.3 at present. Additionally, it should be pointed out that the scaling of the three component graphs in Figure 2.3 are not the same, thus the shape of the slopes cannot be compared. When they are viewed with the same scale both pick-ups and same Tract trips look essentially flat compared to drop-offs.

Given the ambiguity and non-dynamic nature of the results from Model 4, we will argue that one could likely draw more accurate conclusions on the overall effect of TNCs on parking occupancy from Figure 2.1 alone. Collectively looking at Figure 2.1 and Figure 2.2, the impact of TNCs, while not currently large, has the potential to nearly eliminate the need for on-street parkingwith no changes to parking policy or rates. So, then the question is what are some options as our cities age out of on- and off-street parking? Some examples of adaptive development, marketdriven parking demand management, incentive programs, and zoning/policy changes are discussed in the next part of this section of the report. Many of the options discussed will further diminish the need for current or additional parking spaces both on- and off-street.

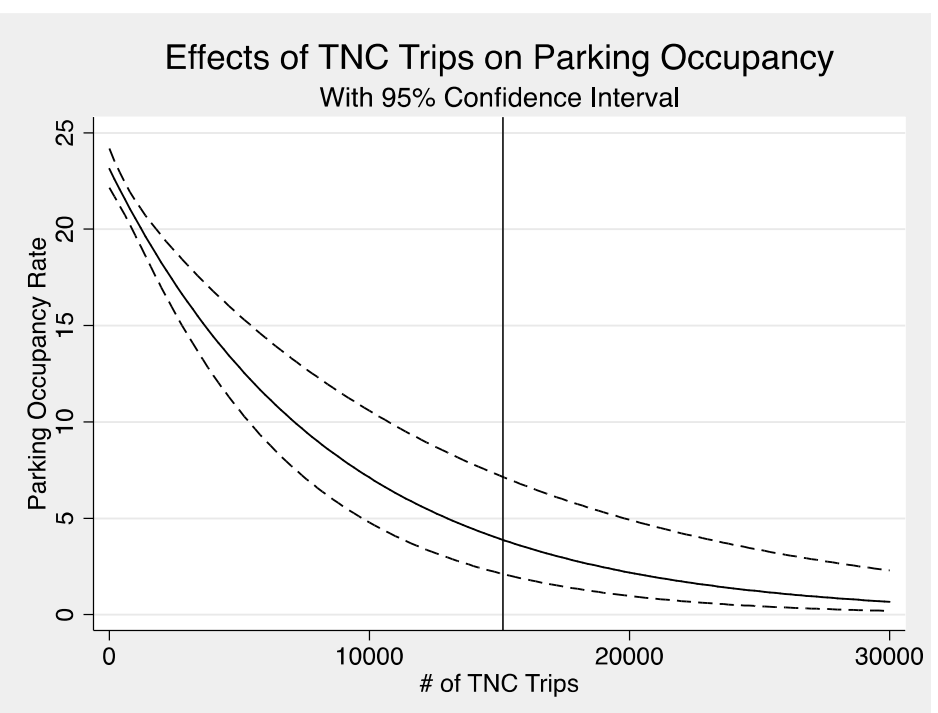

Figure 2.1 


\section{TNC Trips Effects on Parking Occupancy--By Neighborhood With $95 \%$ Confidence Interval}
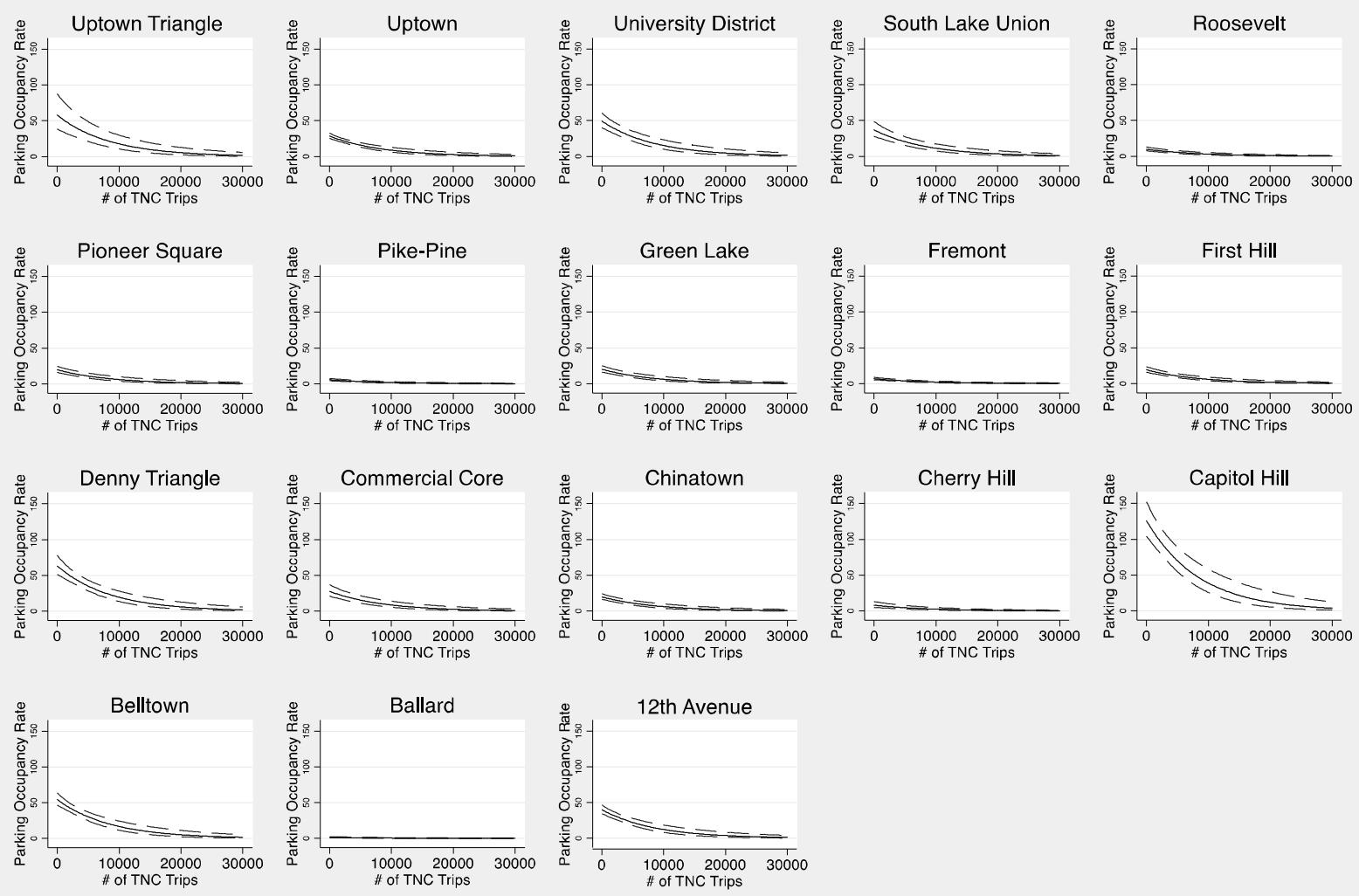

Figure 2.2 


\section{TNC Trips Effects on Parking Occupancy--By Type of Trip \\ With $95 \%$ Confidence Interval}
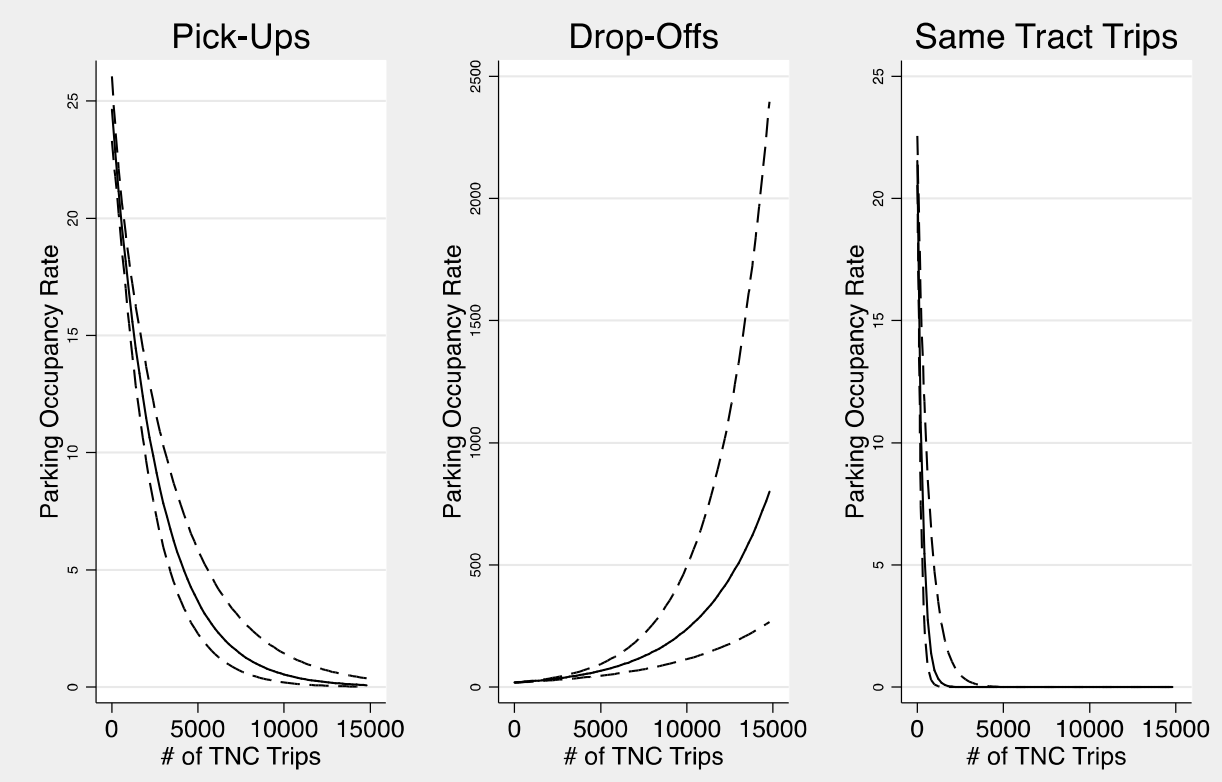

Figure 2.3

\subsection{PARKING GARAGES AND METERS}

\subsubsection{Adaptive Garages}

A leading residential development firm in Los Angeles is constructing a parking garage in their latest structure that will morph with the city as TNCs become more widely used in the downtown area (Vincent 2017). The garage features level floors (instead of more traditional inclined lanes), with higher ceilings which can more easily be converted into other uses, like shops and restaurants, in the future. There is also an underground parking area that is the ideal space for a movie theater or recreation site as the apartment complex welcomes changes in the future regarding parking demand. These adaptations are not as simple as flat floors and higher ceilings, but the placement of stairs and elevators also need to be carefully planned out so that after the garage's conversion, the layout will read like something one would see in an office or another professional setting (Vincent 2017). It has alternatively been suggested that new parking garages that continue to use more traditional garage design features, sloped decks and low ceiling heights, could be built in such a way that they could be easily disassembled or, at minimum, be sure not to attach them directly to the buildings they serve so that they could be torn down without damage to that building.

\subsubsection{Adaptive Parking Meter Pricing}

The city of San Francisco aims to reduce congestion and "cruising” for parking spots in the city by tailoring parking meter prices to fit the demand in a given area. These efforts involve 
extending meter hours and charging more for parking at peak times. This practice, discussed at length by Shoup (2017), has shown real promise in providing the optimal parking occupancy rate. The city has installed in-street sensors to relay real-time parking occupancy data that can be accessed by citizens through a smartphone app. This system helps citizens find parking quickly, but also allows price adjustments based on real-time parking demand. So far, the city has seen a 50 percent reduction in overall cruising in the area and ultimately hope to cap parking occupancy in metered spots at 60-80 percent, on average (Millard-Ball, Weinberger, and Hampshire 2014). However, Pierce and Shoup (2013) found in their analysis that it was not just pricing that changed behavior, but the knowledge that the prices had or would change were key to getting people to change their parking habits. Once people began to understand that it was cheaper close by, but not right next to their destination, they started to park and walk a little further, leaving more parking closer to that destination open but at a higher price. Overall, the prices for parking during SFPark's pilot phase actually decreased. This policy innovation would not necessarily be appropriate for cities that seek to maximize revenue from parking revenue, but rather from those that seek to maximize the efficiency of the use of space and reduce parking-related congestion.

\subsection{PUBLIC TRANSIT INCENTIVES}

\subsubsection{Cashing Out a “Free” Parking Space to Buy Transit}

Shoup (2017) has been banging the drum of no parking spot is actually free, even if the driver is not directly paying for that spot. Transit officials in Washington, D.C., have proposed that employers who have formerly offered free parking spaces to employees now offer them an option to "cash-out" on the value of their space and opt for public transportation, biking, or walking to work (Lazo 2017). Shoup notes that "employer-paid parking is an invitation to drive to work alone” and only gives commute benefits to only those that drive (Lazo 2017). If incentives are offered to workers to give them the freedom to make decisions that override their motivation to drive alone, the transit agency hopes this flexibility will incentivize people to step away from personal vehicle usage and reconnect with local transit options that are more environmentally conscious and sustainable for the city. Freeing up these spaces not only reduces congestion in high-traffic areas but could also provide opportunities for retail space and restaurant expansion (or for curb zones to provide easy access for increasing numbers of TNC riders or for e-commerce delivery) (Lazo 2017).

\subsection{2 “Free” Public Transit}

The City of Columbus, Ohio, has experienced major growth in the past two decades and has recognized its need to reconfigure the way traffic is managed in their downtown core. Officials recognized that only six percent of commuters used public transit of any kind, and have partnered with area businesses to provide free mass transit passes to their workers. In order to do this, businesses will be charged three cents per square mile of space that they take up in the downtown area. The Central Ohio Transit Authority will collect the fee and distribute bus passes to qualifying downtown employees who can use the passes at any hour of the day (in hopes to 
incentivize public transit during non-peak hours as well). This program will allocate $\$ 5$ million annually to nearly 40,000 employees in this growing city. During a three-month test conducted in 2017, researchers observed a 12.2 percent of downtown workers taking the bus, nearly double the 6.4 percent who used this method previously (McGraw 2017).

Paris, France, has instituted a number of recent policy changes to get more people out of their cars and into the transit system. Starting in the fall of 2019, children 11 and under will not have to pay to ride the Metro, while kids older than that will pay discounted fares (O'Sullivan 2019). The city government had already provided free rides for seniors and people with disabilities. The hope is that by providing free rides to kids, parents will see the public transit system as more affordable for their family trips, getting people out of cars and reclaiming the streets for the pedestrians (O’Sullivan 2019).

\subsection{DOING AWAY WITH PARKING MINIMUMS}

Cities across the country are moving toward doing away with or substantially scaling back parking minimums with new developments. The momentum behind these cities moves is likely to be pushed along more swiftly now that, as of February 2019, the Institute of Transportation Engineers (ITE) is publishing new recommendations to eliminate parking minimums and is providing resources to the planners and engineers to change these policies (Belmore 2019, 4). The Arlington, Virginia County Board, has recently passed a plan which would not require apartment complexes near Metro stations to provide as much off-street parking as they have in the past (Teale 2017). The largest U.S. city to do away with parking minimums to date is San Francisco, which did so in late 2018 (Hickman 2018). San Francisco's move allows developers to provide as much parking as they desire, and this is precisely the sort of economically and nonfree parking demand-driven policy that Shoup (2017) has championed. When the cost of parking is decoupled from new construction, the developers can build more units for a lower cost. This is good for residential units and provides more affordable housing. It is good for retail locations, with cheaper rent and cheaper products for people to purchase.

Officials in Oakland, CA, have realized in the past few years that some of their parking spaces in residential development projects were far too costly and frequently went unused. Residents in Oakland have simultaneously recognized that using the BART or a TNC service provide an affordable and smooth alternative to driving or owning personal vehicles downtown, and so have left many of these parking spaces empty in residential areas. The city has adopted new regulations that do not require apartment buildings near BART stations to possess as many dedicated parking spaces in the future. This approach will ultimately allow for more creativity within residential spaces during their construction, and will also save residents money since the cost of parking has not been factored into their monthly rent (Richards 2016). The statewide efforts to mimic this policy have, so far, fallen flat.

A policy often entangled with parking minimums are rental home policies that limit the number of unrelated individuals that live in the same home. These policies are often based on the assumption that if too many unrelated people, like a group of college students or friends, living in a home will create parking problems. These related policies increase the cost of housing, with little empirical evidence to back the claims that they create parking issues. 


\subsection{CREATIVE APPROACHES TO CURB USE}

With a diminished need for parking, as was demonstrated in the Seattle case earlier in this section, cities are able to rethink what these public rights-of-way can be used for that might better contribute to the public good. Cities are converting traffic lanes and curb lanes (formerly on-street parking) for bike or transit lanes, parklets or green space, sustainable stormwater infrastructure, and other uses that increase the utility gained by residents (NACTO 2017; Seattle Department of Transportation 2017). TNC use (and eventually AV use) reduces the need for parking, but still requires drop-off space for users. Pick-up/drop-off curb spaces can help create a more streamlined streetscape with increased opportunities to shift the use of parking spaces. There are several considerations to be made when allocating short-term parking to pick-up/dropoff curb space, specifically, the current built form and activity patterns. The built form refers to the current supply of parking options for a given location, while activity patterns explain parking demand (NACTO 2017; Seattle Department of Transportation 2017).

The use of spatial modeling to analyze Seattle's parking demand based on land use offers an evidence-based solution that can maximize space and utility. This requires determining the number of trips per hour for each land use or location and the average TNC loading time, then equating the number of TNC loading zone spaces that would be required in order to accommodate the peak hour of the day. A study prepared for SDOT in 2017 utilized this modeling methodology to estimate the number of TNC loading zone spaces that would be necessary given the number of trips taken in a given area. Pike-Pine, for example, has a high number of retail spaces in addition to high-rise buildings for condominiums or office space, indicating a high trips-per-hour estimate. However, this study found that around 100 pickup/drop-off spaces could accommodate the neighborhood, which could have implications on how the 1,535 parking spaces in the Pike-Pine neighborhood could be better used (Seattle Department of Transportation 2017). This is not to suggest that all parking would need to be replaced with these pick-up and drop-off zones, but instead, these curb designations could increase the utility of parking spaces while allowing urban spaces to be more productive.

\subsection{FOUR APPROACHES TO CURB SPACE}

The National Association of City Transportation Officials (NACTO) outlined four strategies for curbside management that support the efficient use of our rights-of-way in the emerging curbside economy (NACTO 2017).

\subsubsection{Curb Strategy 1: Flex Zones}

In 2016, Seattle implemented flexible policies that prioritized curb space to accommodate the needs of a given street. For instance, passenger and freight loading took priority over metered parking in busy urban centers. In addition, free, long-term private vehicle storage was seldom supported in city centers, and commuter parking for long durations was not supported at all. 
Cities are shifting from parking lanes to "flex zones" in order to make way for safe bike lanes, reliable transit lanes, curbside deliveries, passenger pick-up opportunities, green stormwater infrastructure, and small public spaces or managed parking. This helps to support policymakers in prioritizing diverse transit options in urban planning. It also acknowledges other important curb uses such as: parklets; pick-up and drop-off for private or for-hire vehicles; or short term, one-hour, multi-hour, or long-term car storage.

\subsubsection{Curb Strategy 2: Transit-Conscious Planning}

This strategy requires transit vehicles, including buses, light rail, and trolleys, to have priority in the rights-of-way. Options to clear the way for transit include marked lanes with signals that clear cars from the designated area, as well as visible approaches for bike lanes. Another issue in bus routing is the need for a clear and open right-turn lane. Leaving a few parking spaces open near the curb for a designated "right-turn pocket" will allow buses to confidently turn and for traffic to flow as usual. All of these strategies combine to form a safer road for not only mass transit vehicles operating in the region but also for pedestrians moving about the right-of-way. Cities are continuing to pursue these types of options to improve transit efficiency despite growing vehicle congestion.

\subsubsection{Curb Strategy 3: Reconfiguring Access and Loading Zones}

Commercial loading zones are a traditional element of the right-of-way, but ride-hailing and autonomous vehicles create additional curbside loading needs for both people and freight. Providing commercial loading zones at the right time of day and at the right place can make it easier and less expensive for businesses to operate them, and can keep bigger trucks out of the way for other cars.

Trucks, taxis, and TNCs cause delays in the curb lane, so negotiating those boundaries is important. Designating loading spaces at high-traffic destinations, while keeping business hours in mind, can help limit these delays. Cities can assign curb spaces to specific uses based on feasible distances from their destination, and reserving the curb on main streets for very shortterm uses. Delivery drivers are expected to enjoy the opportunity to park for longer and for free in designated areas, even if it means they have a short walk to their final destination. Parking illegally and double parking has negative implications for both the delivery company and the product recipient, so this is a positive option for those with regularly scheduled freighting.

\subsubsection{Curb Strategy 4: Considering Tradeoffs}

Residents may be wary of curbside management conversations because they seem to be more worried about the loss of parking spaces than seeing the opportunity parking conversion might create. Cities can aid in this dilemma by highlighting the tradeoffs that exist within this approach. Charging people for a parking permit may seem negative at first glance, but if these permits only allow people to park in specific areas at specific times, then dense neighborhoods 
and downtown cores will be freed from the hectic nature of unavailable parking and frustrated drivers. Highlights from this approach involve providing previously off-limits, off-street parking options to residents in order to make their retail and business experiences more pleasant. This involves allowing people to park behind stores and in private accessory parking spots, which will reduce congestion in front of dense areas of commerce (NACTO 2017; Seattle Department of Transportation 2017).

\subsection{CONCLUSION}

These options for converting curb spaces to other uses and ways in which to encourage more people to get out of their personal vehicles is far from exhaustive, yet it does offer a starting place for the discussion. Free parking is not and has not ever been free (Shoup 2017). As TNCs today, and later AVs, shape how we get around it is clear that both on- and off-street parking demand will continue to change.

The analysis at the start of this section shows how TNCs are already beginning to shows signs of altering driving behavior, as clear patterns of parking occupancy changes are appearing. Figure 2.4, below, shows the yearly median and mean growth in TNC riders in Seattle from 2012 to 2016. Across the five years of the study, the average growth of TNC ridership in Seattle has grown, on average, slightly more than 20 percent month over month, with a median growth rate of about 15 percent. And while the pace of growth in ridership will clearly be hard to sustain at those rates, the raw increase in trips at five percent growth when millions of rides are being provided is still quite staggering. These sustained rates of growth indicate that TNCs are here to stay, will continue to shape the future of mobility, and will reshape our use of the curb and parking on- and off-street.

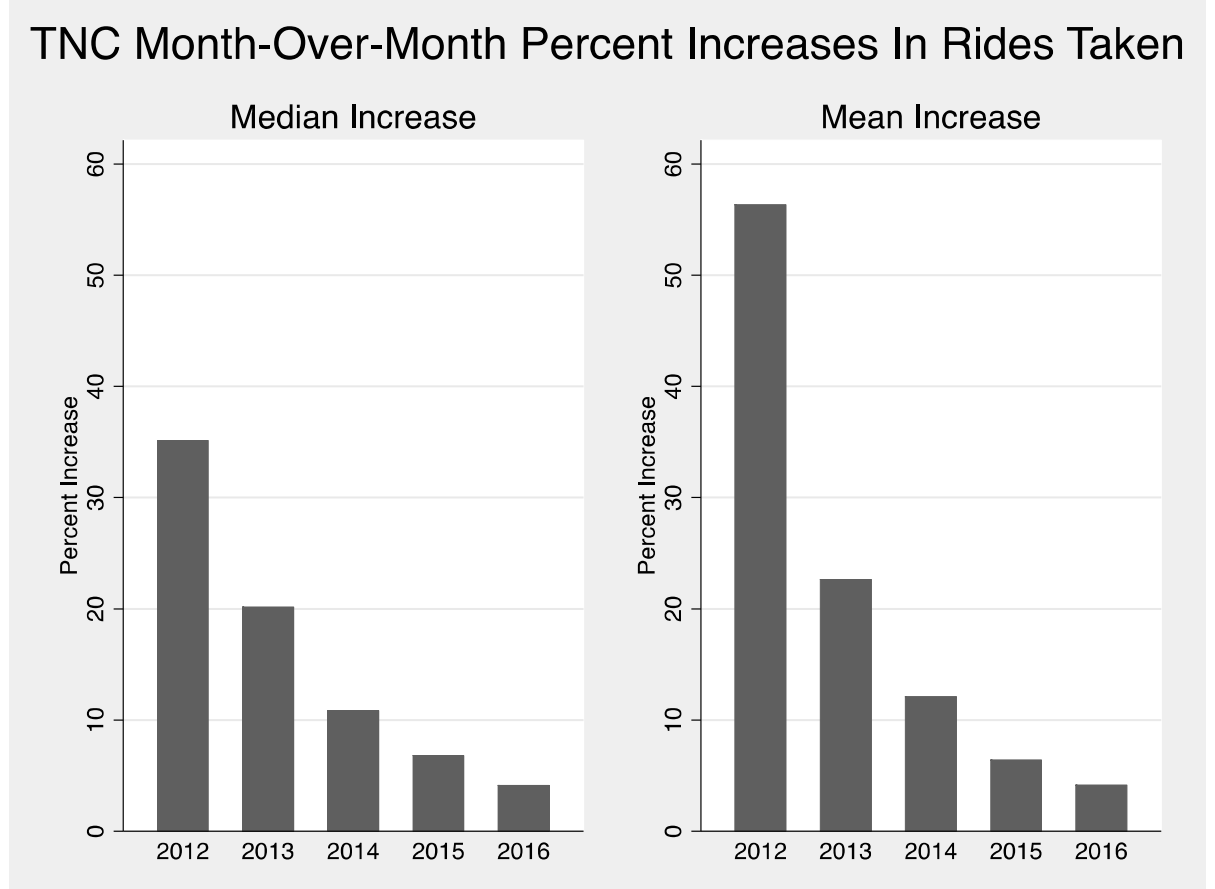

Figure 2.4 


\subsection{THE IMPACTS OF AUTONOMOUS VEHICLES ON LOCAL GOVERNMENT BUDGETING AND FINANCE: CASE OF SOLID WASTE COLLECTION PARAGRAPH FORMAT}

\subsection{INTRODUCTION}

Personal transportation, discussed in the previous two sections of this report, is expected to be dramatically transformed in the coming years. Little attention, however, has been paid to how AVs will transform service delivery (beyond food delivery), and particularly on local government (Clark, Larco, and Mann 2017; Clark and Lewis 2018). This section of the report works to expand upon a largely ignored topic, the impact of AVs on municipal finance and budgeting. Maciag (2017) explored how parking revenues might decline (meters, garages, and citations) in a Governing Magazine article. And Clark, Larco, and Mann provide an outline of budgetary and service impacts but did not address the magnitude of the impacts. Clark and Lewis provided a more in-depth analysis of potential revenue impacts from AVs on parking and transportation.

This section of the report focuses on one service often provided by local governments, residential solid waste collection. Specifically, it will seek to forecast the budgetary impacts of changing how solid waste is collected from one that has been, at times, very labor intensive and dangerous to the employees to one that is completely or mostly automated. In 2017 solid waste collection via AV was already being tested by Volvo in Gothenburg, Sweden (Ackerman 2017). Beyond the AV trucks, a number of other researchers are working on technology that would aid the AVdriven trucks with robots that could fetch trash cans in places where the curbside refuse collection is challenging (Ackerman 2015). A rendering of these robots can be found in Figure 3.1 (though the robots in development do not quite have the Jetson's feel that is seen here). These two innovations lay the groundwork for the elimination of most, but probably not all, human interaction with solid waste bins at the curbside.

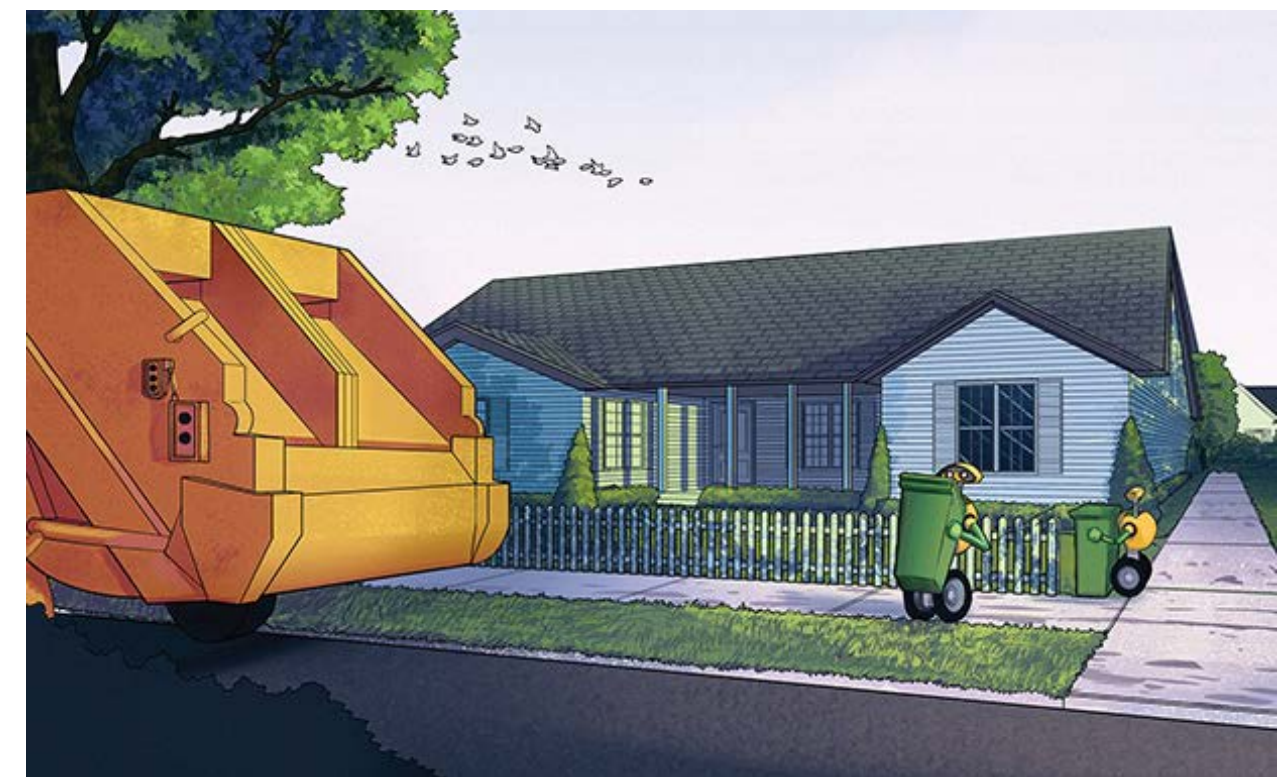

Figure 3.1: Robots bring waste bins to trucks (Source: Volvo via Akerman, 2015) 


\subsection{CURRENT TRENDS TOWARD AUTOMATION}

While AVs may be the future of refuse collection, cities nationwide have been increasing their reliance on solid waste collection trucks that utilized fully or semi-automated arms to pick up and dump refuse into trucks for more than 40 years (Rogoff 2014). These types of trucks often rely upon customers to place trash cans at the street curb, rather than what some cities previously called 'backyard pick-up' where workers might walk onto each property and fetch trash cans and bring the refuse to the truck. This transition reduced the number of trucks required and the size of the crew on each truck. A traditional backyard pick-up, compactor-style truck often relied upon a three-person crew-two people to pick up cans and dump refuse into the trucks and one driver. For the last 40 years, automated trucks typically used just one driver and no others with the vehicle. A study conducted by the EPA (1999) showed an average efficiency increase of over 200 percent when transitioning from backyard pick-up to semi- or fully automated pick-up. The gains were about 275 percent when looking at just the fully automated pickup (the "one-armed bandit" style trucks). This EPA study also found that fully automated fleets were able to reduce the city's capital needs by reducing feet size by an average of about 60 percent. Thus, not only were the fully automated trash pick-up services more efficient (i.e., servicing more houses in a single day), they were also able to lower the number of trucks and, ultimately, employees needed to collect the trash.

Personnel Costs: The shift toward more automated collection, as is evident by the cost and efficiency improvements, is also driven by a desire to reduce "the physical demands on sanitation workers and the career-ending injuries they often suffered” (Rogoff 2014, 1031). Fully automated collection vehicles no longer require the driver to lift trash cans, which increases the pool of potential workers, increases worker comfort as they can just drive and operate the crane from inside the cab, and reduces fatigue and injury to the workers (US Environmental Protection Agency 1999, 28). With a reduction in injuries, governments can see a decrease in workers' compensation cases, a decrease in the reassignment of duties to light duty work, and a reduction in days off/sick time (US Environmental Protection Agency 1999, 28). Moving from backyard collection to semi-automated collection reduced workers' compensation costs for one city "by 52 percent” (US Environmental Protection Agency 1999, 29). Longevity, or lower turnover, is another perk of less impactful work. Rogoff $(2014,1032)$ points out that "it is not surprising to learn that most trash collection workers do not stay in that job past their mid-50s.” Thus, the hiring and training costs of new employees could decrease as well.

The estimates of fewer vehicles being needed in the future are due to trends seen over the last 40 years, where the semi- or fully automated collection has improved the efficiency of collections. Workers in traditional trash collection could end up lifting six tons each day (Rogoff 2014; US Environmental Protection Agency 1999), taking a terrible toll on their bodies and ultimately slowing their ability to collect at a quicker rate. The improvements seen with the automated systems have produced more complex equipment that has higher costs for maintenance "because of increased hydraulic system complexity (but fleet size is typically reduced, so fewer vehicles are usually being maintained)" (US Environmental Protection Agency 1999, 28). We would fully expect that AV-based collection would increase the complexity of machinery to some extent, but again the vehicles would not necessarily be bound by labor rules and could run longer each day, 
reducing the total number of collection trucks that would be needed. Additionally, because of a decrease in injury with both fewer employees operating trucks and picking up rubbish bins, the cost of workers' compensation and liability insurance rates would likely see deep declines (US Environmental Protection Agency 1999, 29; Roland Berger 2016). A study by the Federal Motor Carrier Safety Administration (2014) found that nearly 40 percent of truck crashes were caused by poor decision making by the driver. Thirteen percent of crashes were caused by fatigue, 23 percent from driving too fast, and 17 percent from over-the-counter drug abuse. Consequently, as these trucks maneuvered through the city under AV control, the roll that fatigue, speed, and drug use in crashes would present a decreased risk (assuming they are programmed not to speed).

Capital Costs: The more automated trash collection gets, the higher per unit capital costs go - "on average, the capital cost of an automated side-loader is $20 \%$ more than that of a manual rear loader” (Rogoff 2014, 1032). Solid waste collection systems are adapting despite this higher cost because they see the economic advantage. Looking to the most recent statistics available, "about half of all new waste collection vehicles purchased in 2013 ...were automated one-person trucks. There is a real sense in the solid waste industry today that automated trucks are significantly increasing their share of the new sales in recent years” (Rogoff 2014, 1031-32).

A number of cost estimates have been made on how much additional capital will be required for autonomous trucks. The ranges of these costs are dependent on the level of automation. "Each stage of higher automation brings with it higher system complexity and increasing costs, ranging from 1,800 USD per truck to implement stage one to 23,400 USD per truck all the way to the final stage five" (Roland Berger 2016). While another estimated that automating "dumb” semis could be done for $\$ 30,000$ (Stewart 2016). For semis, this represents about a 15-20 percent increase in the cost of purchasing the vehicles-assuming a $\$ 150,000$ cost of the truck itself. The Roland Berger assessment of cost savings estimates that fuel savings can be realized quickly, saving six percent even before stage-five automation occurs. They also estimate a 90 percent reduction of personnel by the full stage-five implementation of AV trucks. For trash trucks, we might expect a rear loader to cost a little less than $\$ 200,000$ and automated side-loader costing around \$240,000 (Rogoff 2014, 1032; TrashTrucksOnline 2017; WasteMag 2017a, 2017b). Thus, when expenses escalate because of AV capabilities to increase these to $\$ 240,000$ and $\$ 288,000$, respectively.

Limitations: Similar to the challenges engineers face in developing AV technology that can adapt to all driving conditions and hazards, it is likely that not all city streets and trash situations are going to be well-suited for AV collection. Even with today's current automated collection systems (not driven by an AV but by a human), it "does not work well or at all in densely populated areas with on-street parking on collection days or where most people live in mid-tohigh rise multi-family buildings” (Rogoff 2014, 1032). However, Rogoff points out that hybrid approaches can be developed to help to adapt to these conditions that still reduce the number of workers and reduce liability and insurance costs. Some of these challenges seen with the fully or partially automated systems that exist today will be eliminated or reduced as our reliance on automobiles reduces. Many of the problems with fetching trash bins from the curb is that there are cars on the street blocking the trucks and their automated arms from reaching the bins. Findings from Sections 1 and 2 of this report would clearly lead us to believe that fewer cars will 
be parked at the curb in the future, making the need for hybrid systems less vital—and ultimately making AV residential refuse collection more feasible.

Yet despite the challenges of heterogeneity in service delivery, the AV trucks, with spatial awareness and computing power has the potential to be "one where an autonomous system seems like most of the time it can perform better than even an experienced human, and it's one where there are plenty of ways for the system to safely fail, whether by coming to an immediate stop or handing control back to the attending human" (Ackerman 2017).

\subsection{COSTING METHODOLOGY AND DATA}

In this section of the report cost accounting methods are used to create the estimated change in costs for municipal government solid waste collection. Mohr (2015) lays out a range of purposes that cost accounting can serve for governmental organizations. For example, for some, it is used in establishing overhead recovery rates for grants or enterprise funds. Additionally, cost accounting can be used in performance management systems to give those governments a better assessment of programmatic costs as they relate to performance goals. It can be used in dealing with fiscal stress, giving governments the tools to find areas to save. In this report we will use the tools others have used to assess their programmatic or activity costs, and apply those techniques to understand how further automation of collection could change the cost curves for municipal solid waste collection.

Since 1995, the University of North Carolina at Chapel Hill's School of Government's Benchmarking Project has been collecting program-level costing data for municipal governments from around the state of North Carolina. The Benchmarking Project has provided the data for solid waste collection from their most recent survey (2016-17) of these governments for use in this report.

\subsubsection{Cities in the Study}

This report examines two case study cities that are currently delivering different types of solid waste collection and provide a representative example for most cities. Ashville, NC, uses a mix of packer trucks (rear loaders with a larger crew for backyard-style pick-up) and automated trucks with a one-person crew. The other case study city is Chapel Hill, NC. It has a fleet that only includes the packer-style trucks with the larger crews.

\subsubsection{Steps in the Costing Process}

There are a number of steps that are taken in the process to create the forecasted cost estimates of solid waste collection with AVs.

1) Calculate current personnel costs, indirect costs, direct costs, and equipment or capital costs. These costing data are sourced from the Benchmarking Project and serve as the foundation of the next steps in the process. These data were provided by cities to the Benchmarking Project, where the data are further refined and cleaned. 
2) Examine the type and nature of the current level of services being provided by a city. For example, do they currently have a fleet of three rear-loading trucks with three-person crews or a fleet of seven single-operator automated trucks.

3) Make assumptions on the potential for cities with backyard pick-up to move toward more automated collection in the medium and long term. Cities that rely upon backyard pickup because they have streets with a lot of on-street parking, preventing automated trucks from reaching refuse bins without assistance, are not currently good candidates for full automation - but they might in the future should the curb lane clear up as we use fewer personal vehicles.

4) Create cost-escalation criteria for new capital goods (more expensive trucks).

5) Make assumptions on the number of new types of employees who might be needed with a new type of service. While automation may allow for fewer drivers and collectors to be employed, it may require a new class of employee to deal with data management or remote observation of trucks as they collect solid waste.

6) Estimate the reduction in fleet size. We can draw from earlier studies on improved efficiencies of semi- and fully automated trucks that still have drivers to then inform us on service-level improvements that might occur with partially or fully autonomous solid waste collection.

7) Make assumptions on the rapidity of change from current means of collection to partially or fully AV collection in two scenarios, "near future," and "far future."

8) Calculate the change in the cost of all parameters based on the assumptions made in the steps above.

\subsubsection{Assumptions Made for Each City}

For these cities, I have estimated three scenarios to give a range of what the potential impacts might be as these cities have the potential to utilize AV technology for collections: A rosy scenario, middle scenario, and pessimistic scenario. The rosy scenario imagines a world where the technology is adopted more quickly and thus more quickly replaces the current means of collection. The pessimistic scenario imagines a situation where change is slower and consequently potential cost savings are slower to arrive. The middle scenario sits somewhere between these other two scenarios. 
Ashville, NC

Assumptions Summary

$\begin{array}{ccc} & \sim 10 & \sim 15 / 20 \\ \text { Current } & \text { Years } & \text { Years }\end{array}$

Rosy

Capital Costs Increase 20\%

Wage Escalation for Monitoring $\quad 120 \%$

Wage Escalation for Data Analysis $\quad 140 \%$

\# of Truck Monitors

\# of Data Analysts

\# of Trucks (Packers)

\# of Trucks (Automated)

Middle

Capital Costs Increase $\quad 30 \%$

Wage Escalation for Monitoring $\quad 140 \%$

Wage Escalation for Data Analysis $\quad 150 \%$

\# of Truck Monitors

\# of Data Analysts

\# of Trucks (Packers)

\# of Trucks (Automated)

Pessimistic

Capital Costs Increase $\quad 60 \%$

Wage Escalation for Monitoring $\quad 140 \%$

Wage Escalation for Data Analysis $\quad 150 \%$

\# of Truck Monitors

\# of Data Analysts

\# of Trucks (Packers)

\# of Trucks (Automated)

$\begin{array}{lll}0 & 1.75 & 1.75\end{array}$

$\begin{array}{lll}0 & 1 & 2\end{array}$

$1 \quad 1 \quad 1$

$\begin{array}{lll}7 & 6 & 6\end{array}$ 
Chapel Hill, NC

Assumptions Summary

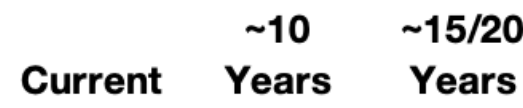

Rosy

Capital Costs Increase

$20 \%$

Wage Escalation for Monitoring $\quad 120 \%$

Wage Escalation for Data Analysis $\quad 140 \%$

\# of Truck Monitors

\# of Data Analysts

\# of Trucks (Packers)

\# of Trucks (Automated)

$\begin{array}{rrrr} & \text { Current } & \begin{array}{c}\sim 10 \\ \text { Years }\end{array} & \begin{array}{c}\sim 15 / 20 \\ \text { Years }\end{array} \\ 20 \% & & & \\ 120 \% & & & \\ 140 \% & & & \\ & 0 & 1 & 1 \\ & 0 & 1 & 1 \\ & 7 & 3 & 1 \\ & 0 & 3 & 3\end{array}$

Middle

Capital Costs Increase $\quad 30 \%$

Wage Escalation for Monitoring $\quad 140 \%$

Wage Escalation for Data Analysis $\quad 150 \%$

\# of Truck Monitors

\# of Data Analysts

\# of Trucks (Packers)

\# of Trucks (Automated)

Pessimistic

Capital Costs Increase $\quad 60 \%$

Wage Escalation for Monitoring $\quad 140 \%$

Wage Escalation for Data Analysis $\quad 150 \%$

\# of Truck Monitors

$0 \quad 1.75 \quad 1.75$

\# of Data Analysts

$0 \quad 1 \quad 2$

\# of Trucks (Packers)

$7 \quad 5 \quad 3$

\# of Trucks (Automated)

$0 \quad 1 \quad 2$

\subsection{RESULTS}

Ashville, NC: Ashville's current fleet already takes advantage of automation with trucks that are able to be operated with a single operator and move very quickly from home to home. Based on the assumptions listed above, the overall estimated long-term savings I have estimated would be between 32 (pessimistic) up to 60 percent (rosy) decline in total cost, depending on the scenario one chooses to go with moving forward (rosy, middle, or pessimistic). Figure 3.2, Figure 3.3, and Figure 3.4 show the results of the changes in assumptions across the three scenarios. The solid lines show the changes in budget allocations (all in current dollars) across the three time periods (today, about 10 years from now, and 15 to 20 years from now). While the dotted lines 
show the change in the number of trucks, I have estimated what would be needed in those time periods.

Solid Waste Collection Changes to Service Delivery \& Cost (Rosy Scenario)

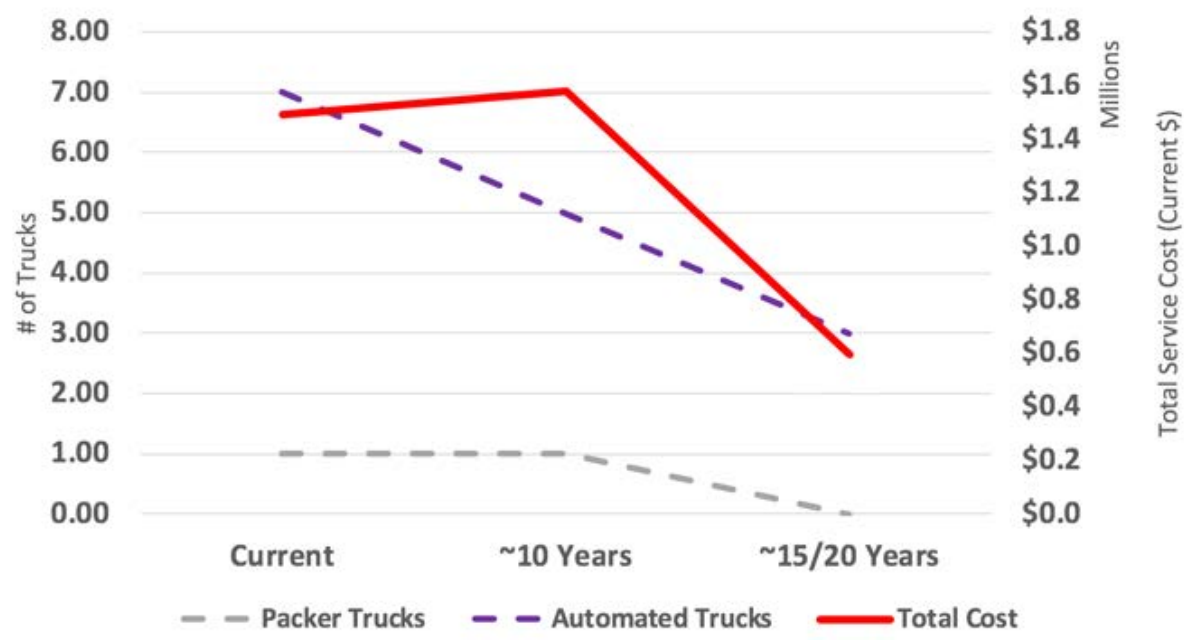

Figure 3.2

Solid Waste Collection Changes to Service Delivery \& Cost (Middle Scenario)

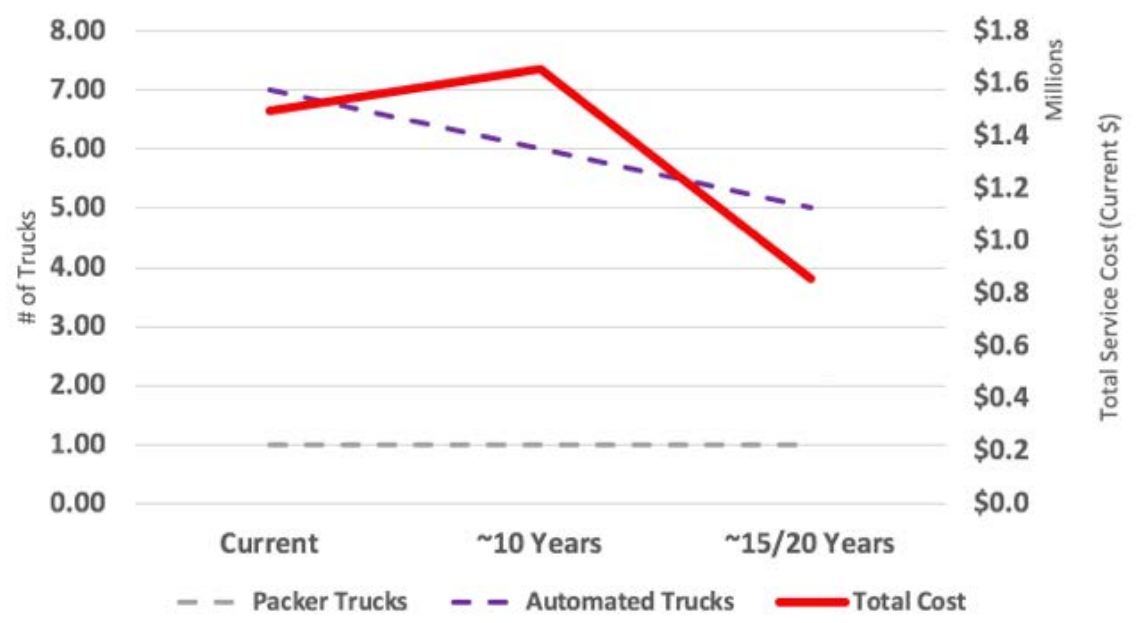

Figure 3.3 


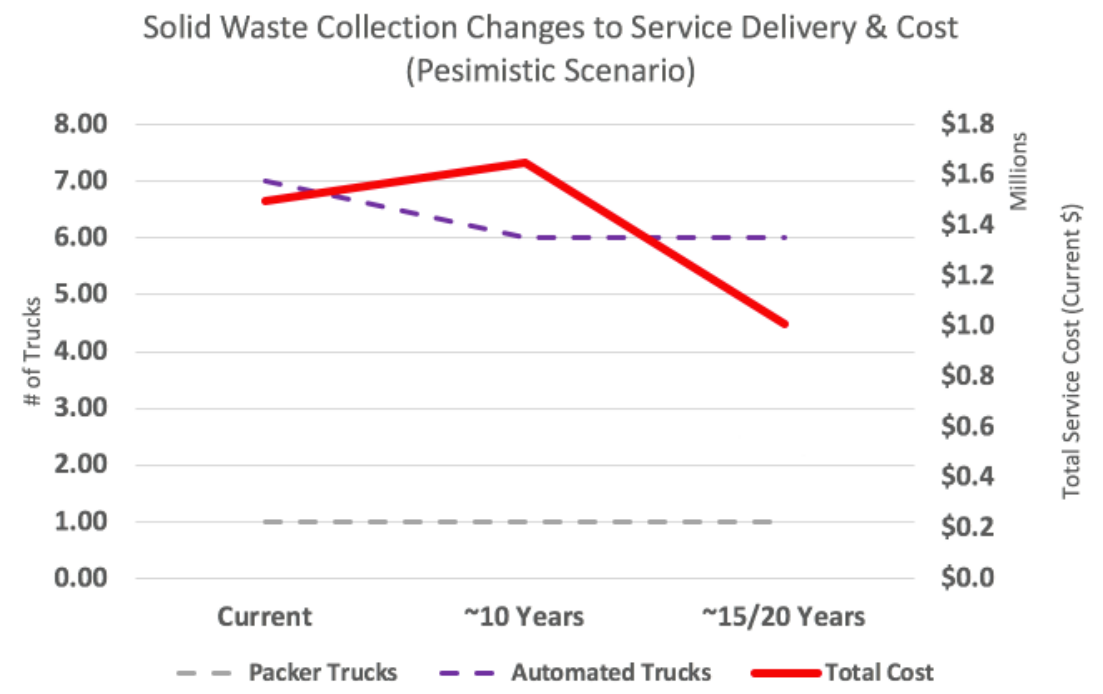

Figure 3.4

Figure 3.5 shows all three scenarios side by side to gain a better understanding of how the three compare. Because Ashville is already highly automated in their collection, I am estimating that the costs will not change dramatically across the three scenarios in the medium term. The assumed increased efficiency of AV-based collection in the long term will provide more cost savings because the number of trucks needed is assumed to decrease, particularly in the rosy scenario - though all three are assumed to benefit substantially from the introduction of AVs.

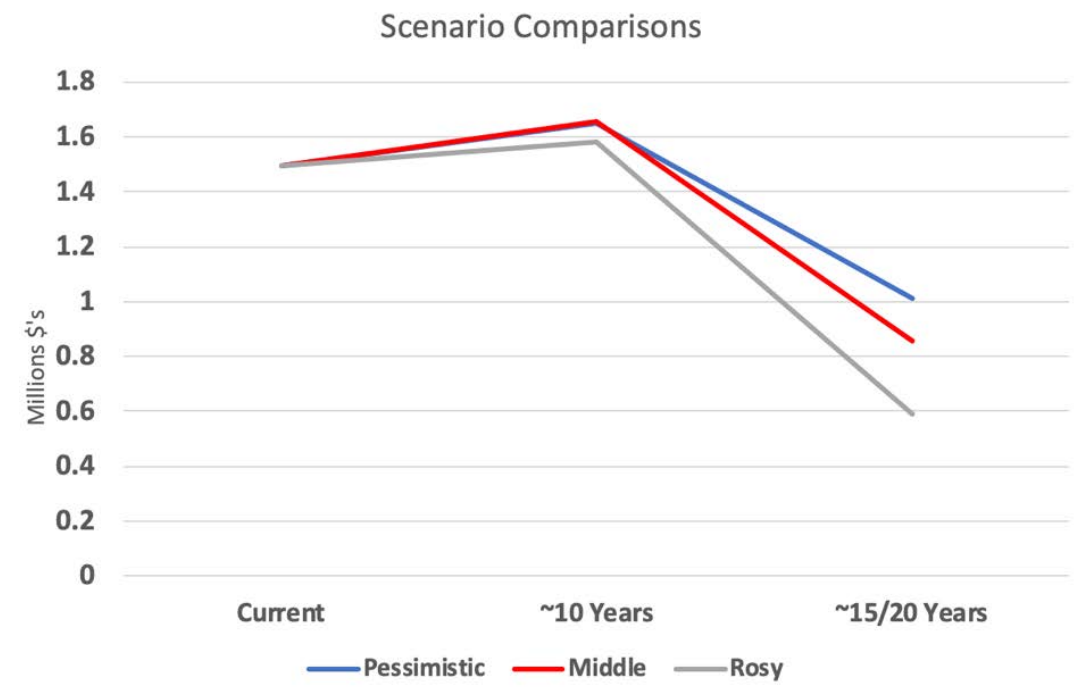

Figure 3.5

Chapel Hill, NC: Chapel Hill is starting from a substantially different point than Ashville is. Its fleet of refuse trucks today is completely comprised of the packer trucks and has larger crews. They are not currently using the one-person automated trucks, likely largely due to cars being between rubbish bins and the trucks on the street. Because we would not expect a full removal of all cars on the road, and thus cars will likely remain parked by the curb beyond 20 years, I have 
not estimated that they could completely do away with the multi-person crews now operating packer trucks. However, newer neighborhoods with wider streets and fewer cars parked on the street to allow for a one-person crew and eventually AV trucks. As a result, the overall cost savings are expected to be between 48 and 56 percent, based on the assumptions listed in the section above.

Figure 3.6, Figure 3.7, and Figure 3.8 show the results of the changes in assumptions across the three scenarios. Again, the solid lines show the changes in budget allocation (all in current dollars) across the three time periods (today, about 10 years from now, and 15 to 20 years from now). While the dotted lines show the change in the number of trucks, I have estimated what would be needed in those time periods.

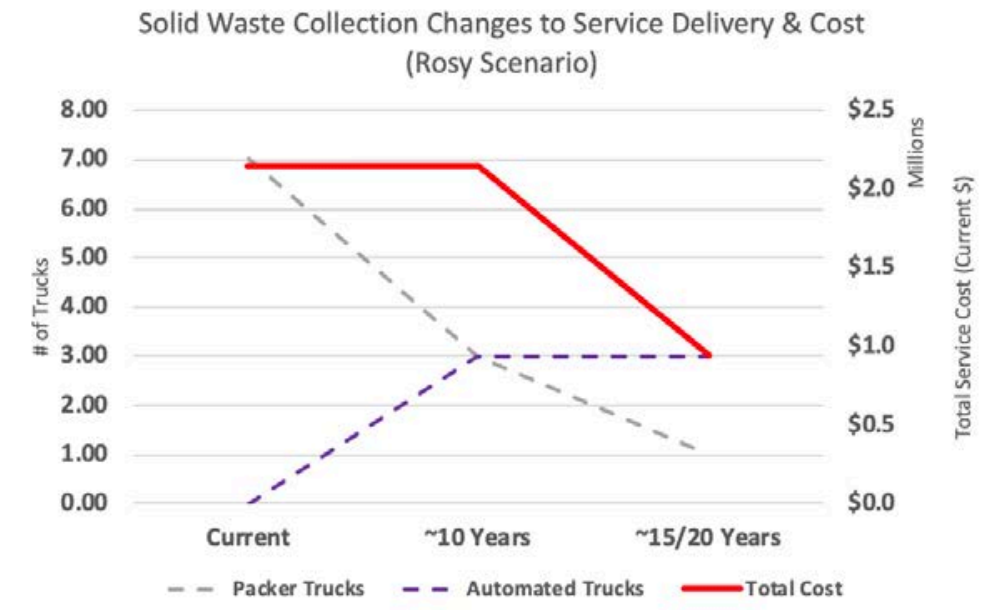

Figure 3.6

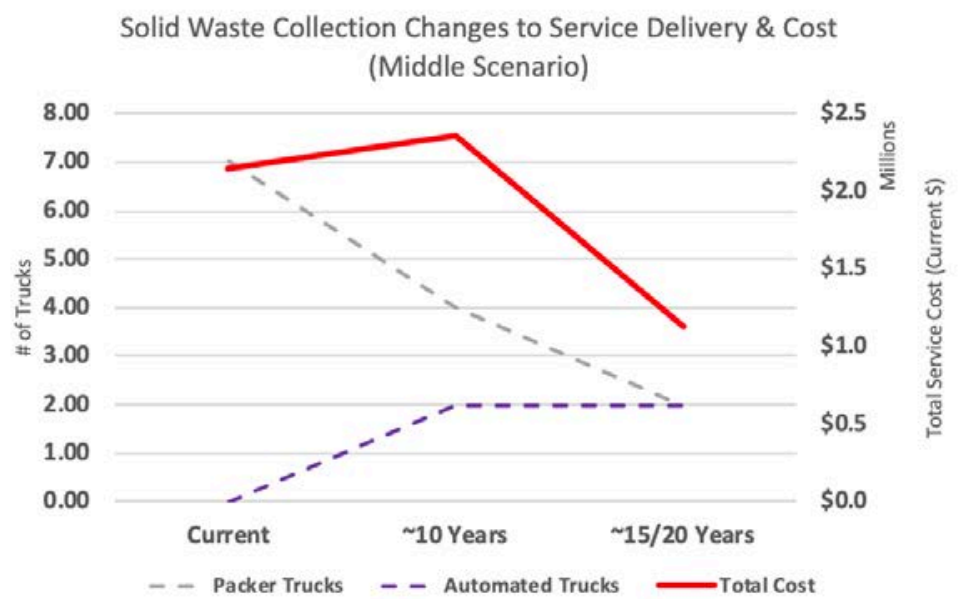

Figure 3.7 


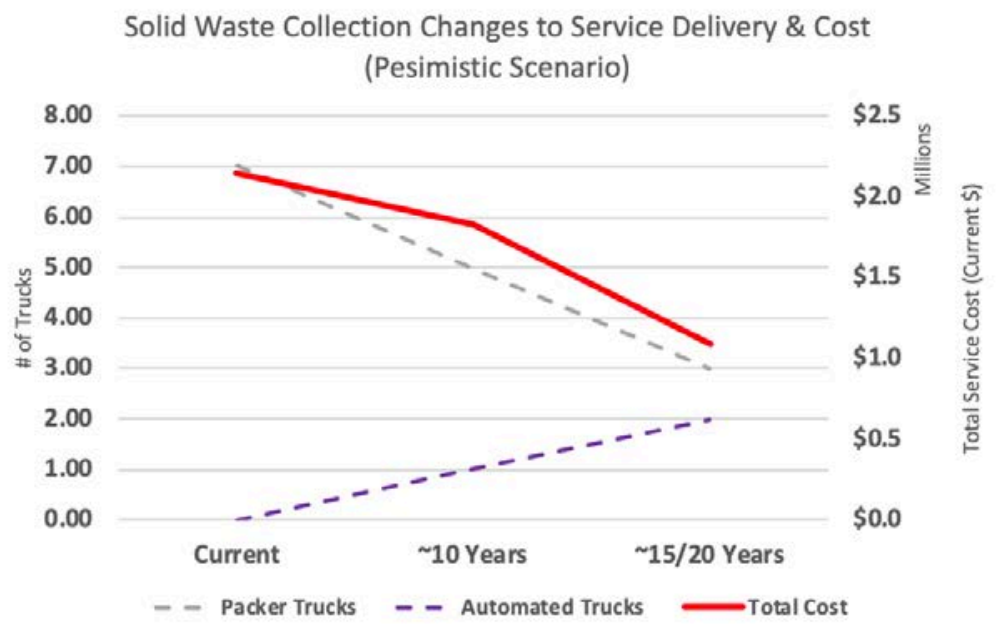

Figure 3.8

Figure 3.9 shows the three scenarios side by side to gain a better understanding of how they compare. Because Chapel Hill is currently using trucks that are less capital intensive (packer trucks), the introduction of more automation is likely to substantially increase their capital expenditures. This is why the pessimistic scenario, which assumes a slower uptake of automation, is actually cheaper in the medium term. The assumed increased efficiency, seen in the rosy scenario, of AV-based collection in the long term will provide more cost savings than the pessimistic scenario because the number of trucks needed is assumed to decrease, particularly in the rosy scenario.

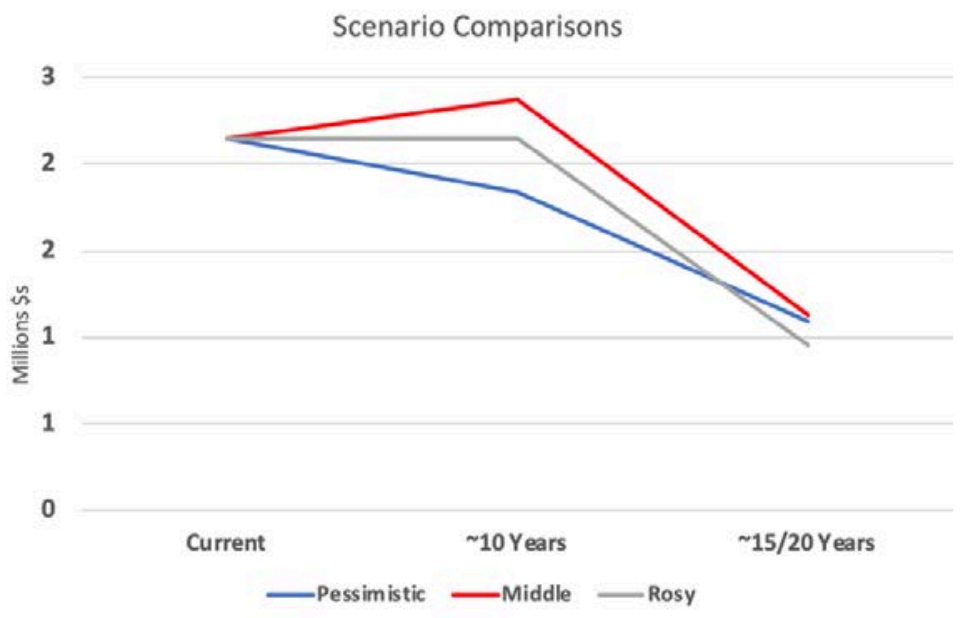

Figure 3.9 


\subsection{DISCUSSION AND CONCLUSION}

At this point in time, it is hard to know the exact timeframe for when a city might be able to buy an AV trash truck, though the Volvo tests are very promising based on publicity from the company. The public demonstrations of Volvo's technology still incorporates a loader with the truck, they just no longer have drivers. This could mean that even cities that today could only reasonably use a three-person crew packer truck could potentially move to one-person crews in the future, as is happening in the tests in Gothenburg.

What I hope readers are able to take away from this costing exercise is that a reasonably straightforward service delivered by a government agency, like the solid waste collection, has the potential to have continued improvements in efficiency — similar to those that were seen decades earlier with the introduction of the one-person automated trucks.

The collection of solid waste is a very taxing career, and turnover and accident rates are high and costly to these municipalities. The progress towards automation to date has given greater longevity to the workers because the stress of the job is lower, which has lowered accident and workers' compensation claims. I would expect a rather gradual transition to the new means of solid waste collection, so massive layoffs around the country are not likely to be an issue. Instead, the natural rates of attrition and retirements in these jobs will simply phase them out without direct economic injury to anyone in those positions. Meanwhile, it is clear that new types of employees will also be needed to assist the trucks and manage massive amounts of data that would be coming in from these trucks. These jobs are likely to be higher paying than the driver and loader positions currently associated with solid waste collection. There remains a substantial amount of uncertainty across a number of different services in local government surrounding the flood of data, so the solid waste collection field will not be alone in trying to understand how to manage and best utilize these data — in addition to the cost. It would benefit local leaders to begin thinking about policies and practices to onboard a workforce that is better trained to handle these data needs, as sensor technology, the internet of things, and other technological advances that create huge amounts of data are already here. The basic task of picking up solid waste is, like so many other services, headed toward an automated task and involves so much more than just brute strength. 


\subsection{REFERENCES}

Ackerman, Evan. 2015. “Trash Hauling Robots Are Cool, But Do We Really Need Them?” IEEE Spectrum: Technology, Engineering, and Science News. September 22, 2015. http://spectrum.ieee.org/automaton/robotics/industrial-robots/volvo-trash-hauling-robots. . 2017. "Volvo Takes the Right First Step in Autonomous Garbage Collection.” IEEE Spectrum: Technology, Engineering, and Science News. May 22, 2017. http://spectrum.ieee.org/cars-that-think/transportation/self-driving/volvo-takes-the-rightfirst-step-towards-autonomous-garbage-collection.

Baruchman, Michelle. 2018. "New On-Street Parking Rates Are Coming to Seattle Neighborhoods. Here's What You'll Pay | The Seattle Times.” Seattle Times, November 23, 2018. https:/www.seattletimes.com/seattle-news/transportation/new-on-streetparking-rates-are-coming-to-seattle-neighborhoods-heres-what-youll-pay/.

Belmore, Bruce. 2019. “ITE Journal - February 2019.” February 2019. http://www.nxtbook.com/ygsreprints/ITE/G103582_ITE_February2019/index.php\#/4.

Brodsky, Jessica S. 2016. “Autonomous Vehicle Regulation: How An Uncertain Legal Landscape May Hit The Brakes On Self-Driving Cars.” Berkeley Technology Law Journal 31: 851-78.

City of Seattle, Washington. 2018. "2018 Adopted Budget--General Subfund Revenue Overview.” City Budget Office, City of Seattle. http://www.seattle.gov/financedepartment/18adoptedbudget/documents/revenueoverview .pdf.

Clark, Benjamin Y., Nico Larco, and Roberta F. Mann. 2017. "The Impacts of Autonomous Vehicles on Local Government Budgeting and Finance.” SSRN Scholarly Paper ID 3009840. Rochester, NY: Social Science Research Network. https://papers.ssrn.com/abstract=3009840.

Clark, Benjamin Y., and Rebecca Lewis. 2018. "Future Transport and City Budgets: Getting Bottom-Line Savvy In An Uncertain Future.” In Disruptive Transport: Driverless Cars, Transport Innovation and the Sustainable City of Tomorrow, 1st Edition (Hardback) Routledge, edited by William Riggs. Routledge. https:/www.routledge.com/DisruptiveTransport-Driverless-Cars-Transport-Innovation-and-theSustainable/Riggs/p/book/9781138613164.

Connery, Brian. 2016. “Autonomous Vehicles and Municipal Bonds.” New York, NY: Morgan Stanley.

Fagnant, Daniel J., and Kara Kockelman. 2015. "Preparing a Nation for Autonomous Vehicles: Opportunities, Barriers and Policy Recommendations.” Transportation Research Part A: Policy and Practice 77 (July): 167-81. https://doi.org/10.1016/j.tra.2015.04.003.

Federal Motor Carrier Safety Administration. 2014. "The Large Truck Crash Causation Study Analysis Brief.” Text. Federal Motor Carrier Safety Administration. April 16, 2014. https://www.fmcsa.dot.gov/safety/research-and-analysis/large-truck-crash-causationstudy-analysis-brief.

Glancy, Dorothy J. 2015. “Autonomous and Automated and Connected Cars - Oh My: First Generation Autonomous Cars in the Legal Ecosystem.” Minnesota Journal of Law, Science and Technology 16: 619. 
Glus, Peter, Tanya Bhatia, Caroline Caglioni, Leland Greenfield, Ellie Killiam, Anna Kramer, Mary Penny, et al. 2017. "Driverless Future: A Policy Roadmap for City Leaders.” 01633241. https://www.arcadis.com/en/united-states/our-perspectives/driverless-future/.

Gutman, David. 2018. “Study Shows Seattle Has Plenty of Parking. So Why Can’t You Find a Spot? | The Seattle Times.” Seattle Times, July 14, 2018. https://www.seattletimes.com/seattle-news/transportation/study-shows-seattle-has-plentyof-parking-so-why-cant-you-find-a-spot/.

Hickman, Matt. 2018. "Why San Francisco Nixing Parking Minimums Is a Win for the Environment.” MNN - Mother Nature Network. December 5, 2018. https://www.mnn.com/green-tech/transportation/blogs/why-san-francisco-nixing-parkingminimums-win-environment.

Lazo, Luz. 2017. “D.C. Wants Employers to Pay Workers Not to Drive to Work.” Washington Post, March 17, 2017. https://www.washingtonpost.com/news/drgridlock/wp/2017/03/17/d-c-wants-employers-to-pay-workers-not-to-drive-to-work/.

Lewis, Paul, Gregory Rogers, and Stanford Turner. 2017. "Beyond Speculation Automated Vehicles and Public Policy.” Washington, D.C.: Eno Center for Transportation. https://www.enotrans.org/wp-content/uploads/2017/04/AV_FINAL.pdf.

Maciag, Mike. 2017. “How Driverless Cars Could Be a Big Problem for Cities.” Governing Magazine. August 1, 2017. http://www.governing.com/topics/finance/gov-cities-trafficparking-revenue-driverless-cars.html.

McGraw, Daniel. 2017. "Free Bus Passes for Workers: Columbus’s Big Idea to Relieve a Congested Downtown.” The Guardian, October 3, 2017, sec. Cities. https://www.theguardian.com/cities/2017/oct/03/free-public-transport-downtownworkers-columbus-car.

Millard-Ball, Adam, Rachel R. Weinberger, and Robert C. Hampshire. 2014. "Is the Curb 80\% Full or 20\% Empty? Assessing the Impacts of San Francisco's Parking Pricing Experiment.” Transportation Research Part A: Policy and Practice 63 (May): 76-92. https://doi.org/10.1016/j.tra.2014.02.016.

Mitteregger, Mathias, Aggelos Soteropoulos, Johann Bröthaler, and Fabian Dorner. 2019. "Shared, Automated, Electric: The Fiscal Effects of the 'Holy Trinity.'” In REAL CORP 2019-IS THIS THE REAL WORLD? Perfect Smart Cities vs. Real Emotional Cities. Proceedings of 24th International Conference on Urban Planning, Regional Development and Information Society, 627-635. CORP-Compentence Center of Urban and Regional Planning.

Mohr, Zachary T. 2015. "An Analysis of the Purposes of Cost Accounting in Large U.S. Cities.” Public Budgeting \& Finance 35 (1): 95-115. https://doi.org/10.1111/pbaf.12059.

NACTO. 2017. "Curb Appeal: Curbside Management Strategies for Improving Transit Reliability.” National Association of City Transportation Officials. https://nacto.org/tsdg/curb-appeal-whitepaper/.

National League of Cities. 2017. “Autonomous Vehicles: A Policy Preparation Guide.” Washington, D.C.: Center for City Solutions, National League of Cities. http://www.nlc.org/sites/default/files/201704/NLC\%20AV\%20Policy\%20Prep\%20Guide\%20web.pdf.

O’Sullivan, Feargus. 2019. “Coming Soon to Paris: Kids Ride Free on Public Transportation.” CityLab. January 18, 2019. https://www.citylab.com/transportation/2019/01/paris-metrotickets-prices-kids-bus-ride-disability-fares/580759/. 
Pierce, Gregory, and Donald Shoup. 2013. “Getting the Prices Right.” Journal of the American Planning Association 79 (1): 67-81. https://doi.org/10.1080/01944363.2013.787307.

Richards, Kathleen. 2016. "Oakland Steers Away From Cars.” Oakland Magazine, October 26, 2016. http://www.oaklandmagazine.com/November-2016/Oakland-Steers-Away-FromCars/.

Rogoff, Marc J. 2014. “Solid Waste Collection Automation in the United States.” Waste Management \& Research 32 (11): 1031-33. https://doi.org/10.1177/0734242X14558164.

Roland Berger. 2016. “Automated Trucks - The next Big Disrupter in the Automotive Industry?” Roland Berger. 2016. https://www.rolandberger.com/en/press/AutomatedTrucks-\%E2\%80\%93-The-next-big-disrupter-in-the-automotive-industry.html.

Schaller, Bruce. 2018. "The New Automobility: Lyft, Uber and the Future of American Cities.” Brooklyn, NY: Schaller Consulting. http://www.schallerconsult.com/rideservices/automobility.pdf.

Scharnhorst, Eric. 2018. "Quantified Parking: Comprehensive Parking Inventories for Five US Cities.” Research Institution for Housing America. https://www.documentcloud.org/documents/4598972-RIHA-Parking-Report.html.

Seattle Department of Transportation. 2017. “NEW MOBILITY PLAYBOOK.” Seattle, WA: Seattle Department of Transportation. https://newmobilityseattle.info/storage/app/media/Documents/newmobilityplaybookfurth eractionsappendices.pdf.

Shoup, Donald. 2011. The High Cost of Free Parking, Updated Edition. 1 edition. Chicago: Routledge. . 2017. The High Cost of Free Parking : Updated Edition. Routledge. https://doi.org/10.4324/9781351179782.

Stewart, Jack. 2016. “\$30K Retrofit Turns Dumb Semis Into Self-Driving Robots.” WIRED. May 17, 2016. https://www.wired.com/2016/05/otto-retrofit-autonomous-self-drivingtrucks/.

Teale, Chris. 2017. "Board Approves Reduced Parking Plan at New Buildings Near Metro Stations.” ARLnow.Com - Arlington, Va. Local News (blog). November 20, 2017. https://www.arlnow.com/2017/11/20/board-approves-reduced-parking-plan-at-newbuildings-near-metro-stations/.

Terry, Jacob, and Chris Bachmann. 2019. "Quantifying the Potential Impact of Autonomous Vehicle Adoption on Government Finances.” Transportation Research Record, April, 0361198119837218. https://doi.org/10.1177/0361198119837218.

TrashTrucksOnline. 2017. "Rear Loaders.” 2017. http://www.trashtrucksonline.com/category/182/GARBAGE-TRUCKS-RearLoaders.html.

US Energy Information Administration. 2019. “U.S. All Grades All Formulations Retail Gasoline Prices (Dollars per Gallon).” 2019. https://www.eia.gov/dnav/pet/hist/LeafHandler.ashx?n=PET\&s=EMM_EPM0_PTE_NU S_DPG\&f=M.

US Environmental Protection Agency. 1999. “GETTING MORE FOR LESS: IMPROVING COLLECTION EFFICIENCY.” Washington, D.C.: US Environmental Protection Agency. https://bit.ly/2Gb2DM9.

Vincent, Roger. 2017. "When Car Ownership Fades, This Parking Garage Will Be Ready for Its next Life | The Seattle Times.” Seattle Times, April 25, 2017. 
https://www.seattletimes.com/business/when-car-ownership-fades-this-parking-garagewill-be-ready-for-its-next-life/.

WasteMag. 2017a. “New 2016 Autocar ACX64 Automated Side Loader Garbage Truck.” 2017. http://www.wastemag.com/shop/classifieds/vehicles/garbage-trucks/automated-sideloaders/view/2459/new-2016-autocar-acx64-automated-side-loader-garbage-truck.

— . 2017b. "Used Rearload Garbage Trucks For Sale | Used Rear Loaders For Sale | RearLoad Trash Trucks For Sale.” 2017.

http://www.wastemag.com/shop/classifieds/vehicles/garbage-trucks/rearloaders?minyear=2017\&maxyear $=2018$. 


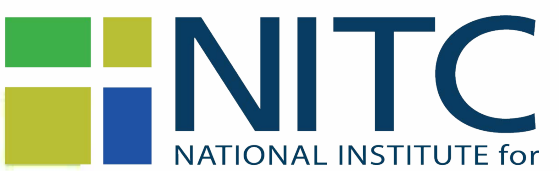

TRANSPORTATION and COMMUNITIES

Transportation Research and Education Center

Portland State University

1900 S.W. Fourth Ave., Suite 175

Portland, OR 97201 